2020-11-15

\title{
Wave energy converter physical model design and testing: The case of floating oscillating-water-columns
}

Portillo, JCC

http://hdl.handle.net/10026.1/16247

10.1016/j.apenergy.2020.115638

Applied Energy

Elsevier BV

All content in PEARL is protected by copyright law. Author manuscripts are made available in accordance with publisher policies. Please cite only the published version using the details provided on the item record or document. In the absence of an open licence (e.g. Creative Commons), permissions for further reuse of content should be sought from the publisher or author. 


\title{
Wave energy converter physical model design and testing: The case of floating oscillating-water-columns
}

\author{
J.C.C. Portillo a,* K.M. Collins ${ }^{b}$, R.P.F. Gomes ${ }^{a}$, J.C.C. Henriques ${ }^{\text {a }}$, L.M.C. Gato ${ }^{\text {a }}$, B.D. Howey ${ }^{\text {b }}$, \\ M.R. Hann ${ }^{\text {b}}$, D.M. Greaves ${ }^{b}$, A.F.O. Falcão ${ }^{a}$ \\ a IDMEC, Instituto Superior Técnico, Universidade de Lisboa, Av. Rovisco Pais 1, 1049-001 Lisboa, Portugal \\ ${ }^{\mathrm{b}}$ University of Plymouth, Drake Circus, PL4 8AA, UK
}

\section{ARTICLEINFO}

\section{Keywords:}

Wave energy

Floating oscillating-water-column

Coaxial-duct OWC

Spar-buoy OWC

Physical model design

Experimental wave tank testing

\begin{abstract}
A B STRACT
The quest for exploiting the ocean resources and understanding its behaviour has been a challenge with increasing needs for innovation and technology. Model testing is an essential step in offshore renewable energy technology development. It involves challenges that require experience and guidance. Costly mistakes might arise with the subsequent waste of time and resources. This paper presents the model design and testing processes as part of wave energy projects and the results of experimental testing of two types of oscillating- water-column (OWC) wave energy converters (WEC). The model design aims at the creation of a reduced-scale model to simulate the physical phenomena found in full-scale devices. It is a process that requires several skills and an adequate compromise among all variables. This design involves several approaches as different physical phenomena do not follow the same similarity conditions, requiring adjustments in scale, materials, and other relevant properties. Besides, the model testing process comprises the necessary planning and actions to execute the tests and post-processing of data. This process is addressed here through model design and testing of two WECs: the coaxial-duct and the sparbuoy OWCs. The configurations have been designed and studied for large-scale energy production and small-scale power in oceanographic applications. Although the devices are both OWCs, the designs exhibit significant differences. The development process of the models and results are presented for the two OWC devices. Freedecay tests, hydrodynamic performance and mooring tension results are presented and discussed. These may serve as guidelines and numerical modelling validation.
\end{abstract}

\section{Introduction}

Experimental testing is essential in the development of wave energy converters (WECs). Sea trials are usually prohibitively expensive [1], and should be preceded by small-to-medium scale testing [2]. Although this does not simulate all features and performance of prototypes accurately [3], it provides a valuable source of information to researchers, developers and investors/entrepreneurs.

Model testing involves challenges that require experience and guidance. Costly mistakes might arise with the subsequent waste of time and resources. This paper presents two test cases to illustrate in detail the proposed methodologies.

The technological development of wave energy conversion has been taking advantage of new knowledge and accumulation of experience. The technology readiness level (TRL) framework, initially conceptualised by NASA [4] for space technology, has been used and adapted to wave energy technology development. Considerable efforts have been made to apply TRLs to WECs, for example, Ref. [2] where five phases were proposed: (1) validation model, (2) design model, (3) process model, 4) prototype device, and (5) demonstration unit. About the same time, guidelines for testing, costs estimations and recommendations for presenting results appeared in Ref. [5]. The guidelines were prepared based on principles developed as part of the Danish Wave Energy Program 1997-2001. Subsequent adaptations were done in Refs. [6-8], with updated panoramas of the ongoing wave energy developments or completed at the time. Refs. [8,9] made contributions more focused on oscillating-water-column (OWC) WECs. More recent documents summarising guidelines and giving more precise recommendations on the development of WECs can be found in Refs. [10-12], which also provide detailed guidance on model testing for WECs. SANDIA National Laboratory produced guidelines to assess the technology performance 


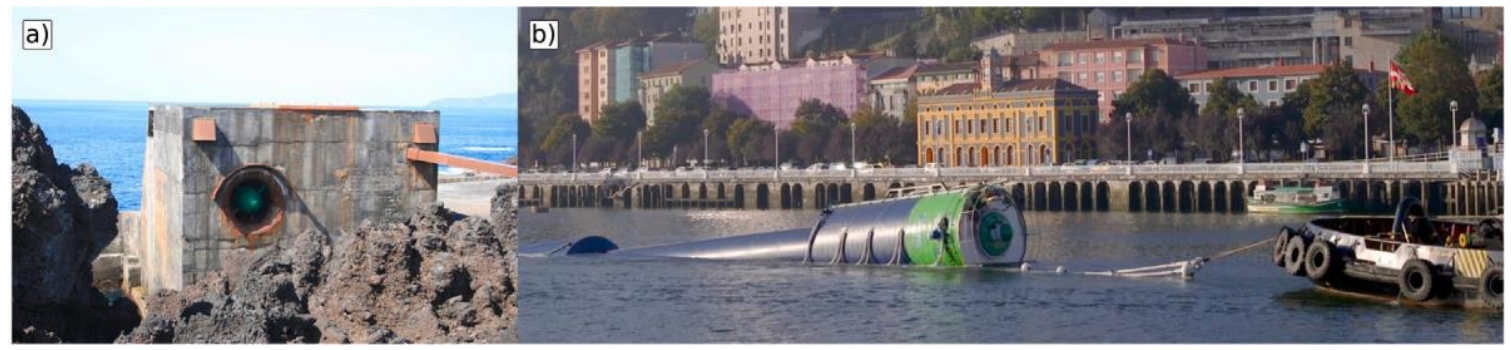

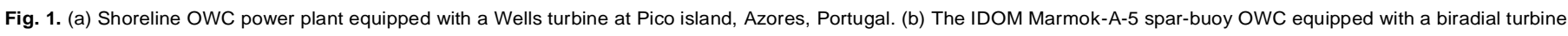
being towed for deployment at BiMEP test site, Basque Country, Spain.

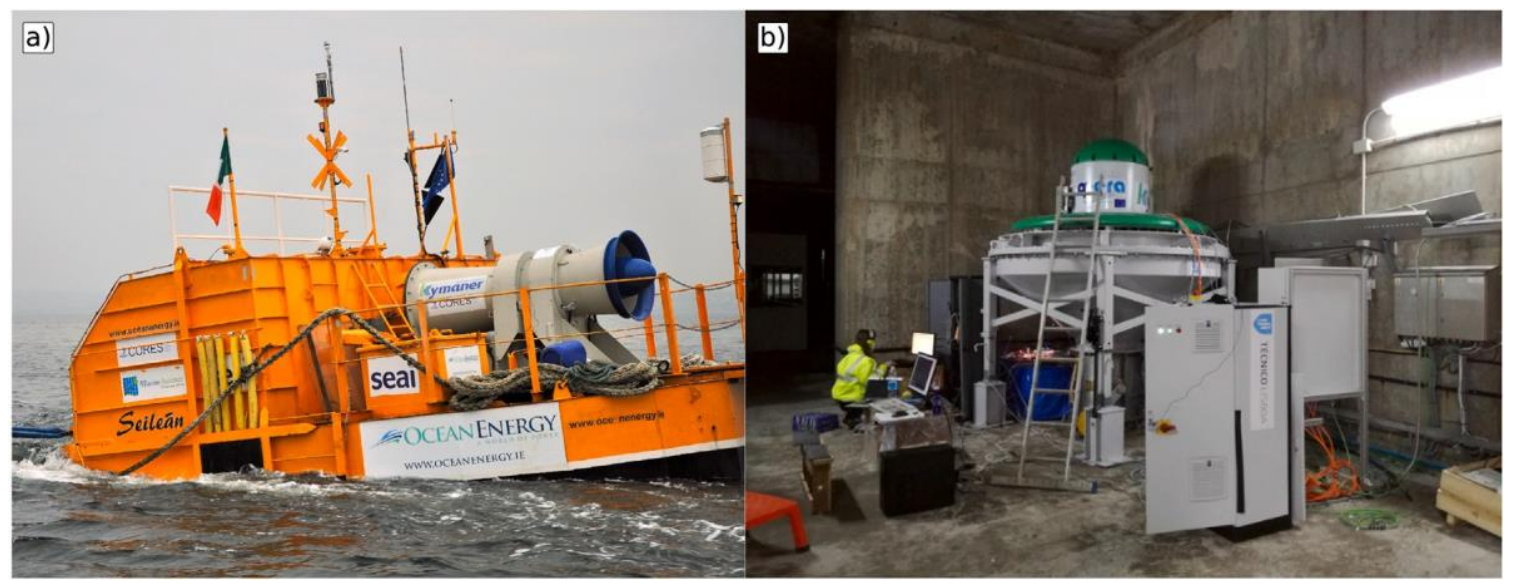

Fig. 2. (a) The Backward-Bent-Duct-Buoy testing at the Galway Bay, Ireland, with an axial impulse turbine. (b) The biradial turbine testing at Mutriku wave power plant, Spain.

level (TPL) considering a wide range of factors associated with the techno-economics of extensive exploitation of wave energy [13].

Despite the progress so far, a clear need for guidance to acceler- ate the development of WECs continues to exist. The IEC TC114 in conjunction with the IEA-Ocean Energy Systems are working towards the development of standards for this emerging industry. A set of best practices and recommended procedures for WECs testing at the preprototype stage are provided in Ref. [14]. Other groups prepared general guidelines like the ones in Ref. [15]. The European Commission (EC) funded EquiMar project, which sought to provide a rational suite of protocols to accelerate WECs development [16]. The EC has also implemented a broader definition of the TRL framework for the $\mathrm{H} 2020$ programme [17].

Several EC projects funded the construction of OWCs. Fig. 1 shows two of those prototypes. The Pico pilot plant was completed in 1999 and operated until 2018, Fig. 1a. It was the first wave power plant designed and constructed to permanently supply an electrical grid [18]. The more recent IDOM Marmok-A-5 OWC spar-buoy prototype was tested at the BiMEP test site, Basque Country, Fig. 1b. It was equipped with a biradial self-rectifying air turbine coupled to a $30 \mathrm{~kW}$ electrical generator [19]. Another floating OWC device is shown in Fig. 2a. It is a 1:4-scale model based on the Backward-Bent-Duct-Buoy (BBDB) due to Yoshio Masuda [20]. A full-scale version, OE35, with a rated power of $1 \mathrm{MW}$, was recently deployed off the Oahu island, Hawaii. A review on OWC technology and air turbines can be found in Ref. [21].

Physical modelling of floating OWCs is reported in the recent literature. Refs. [22,23] compare experimental and numerical results for an OWC spar-buoy. Experimental and numerical results for the Tuperwave OWC spar-buoy with check valves and unidirectional air turbine are reported in Ref. [24], where the spring-like air compressibility effects are accounted for through an extra volume added as part of the air chamber. Ref. [25] describes model testing of a new floating semisubmersible structure which combines three OWCs with a $5 \mathrm{MW}$ wind turbine. An experimental study of a floating OWC with tension legs is presented in Ref. [26]. The geometry was similar to typical breakwater geometries. Ref. [27] presents the numerical and experimental results of a hybrid TLP platform wind/wave with three OWCs WECs. In Ref. [28] is presented a review of the progress on the use of dielectric elastomer generators as PTOs in WECs, in which it is also shown the application to OWCs. Other experimental studies on floating OWCs classified by the evaluation of specific features are: (i) Ref. [29] studies how the OWC performance is affected by moorings and by different levels of turbine damping. (ii) Refs. [30,31] involve multichamber OWCs, multiple OWCs in one floating structure and arrays of floating OWCs. (iii) Refs. [32-35] concern OWCs as part of hybrid systems, multi-use platforms or floating breakwaters. (iv) Refs. [19,36] address the control of PTOs for floating OWCs. (v) Ref. [37] involves the characterisation of floating OWCs. (vi) Refs. [38,39] address air compressibility effects.

The present paper is focused on guidance for model testing of WECs, based on a process approach. The contributions of the present work are:

- a process summary for different stages of model testing of WECs to serve as guidance for developers and scientific community;

- model designs departing from idealised designs with test results that can serve as reference models information;

- a systematic description of the tank testing process;

- test results summarised for selected designs, which may serve to support or validate numerical models and to improve the design of these technologies.

The paper is organised into four main sections. Section 2 presents an overview of wave energy projects, and the description of the model design and testing sub-process, with essential steps and common issues. Section 3 presents systems selected for this work and the processes involved in the design, manufacturing, verification and testing of scaledmodels. Results are presented in Section 4. Conclusions are drawn in Section 5 . 

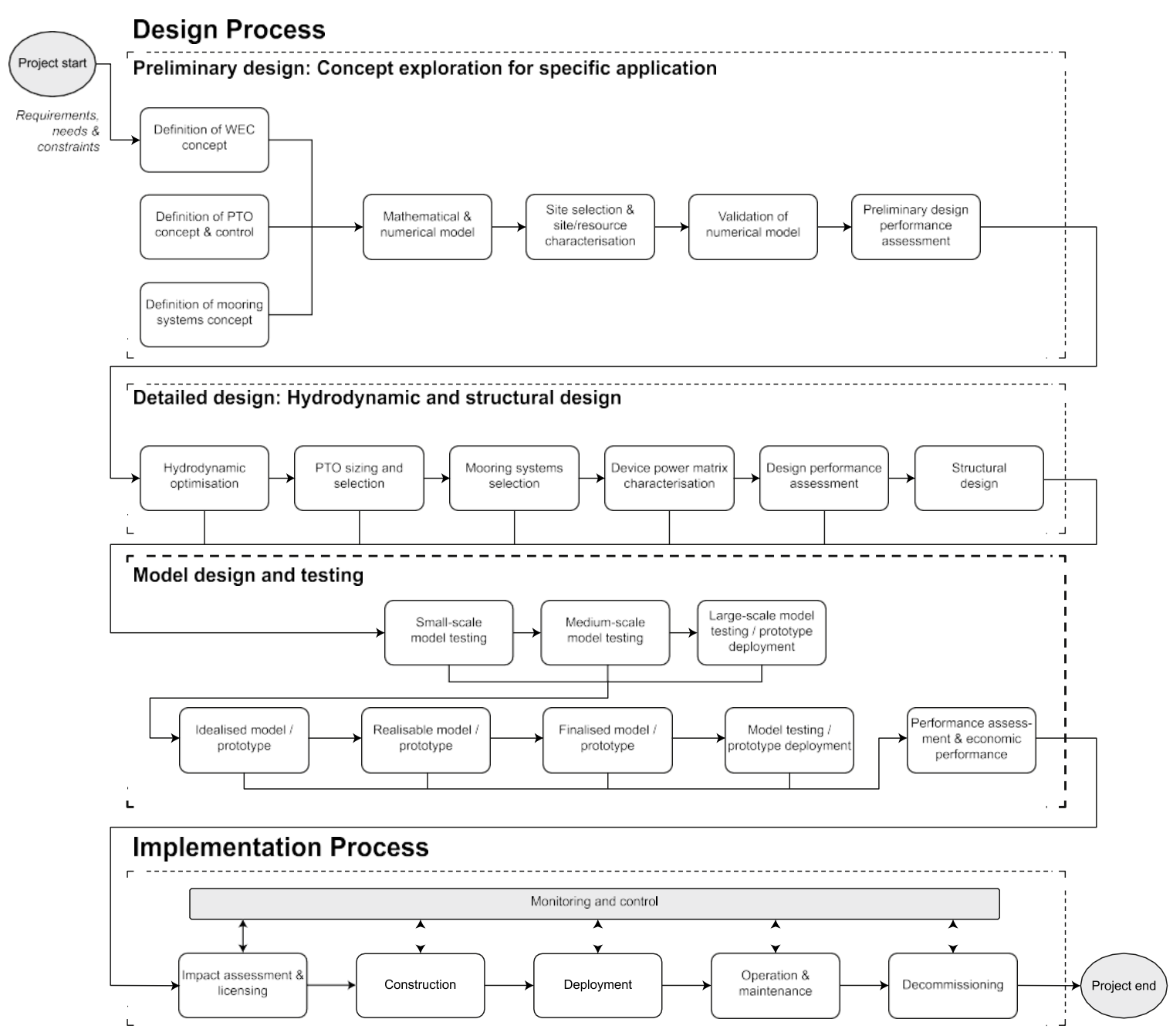

Fig. 3. Schematic representation of the life cycle of a wave energy project. Source: adapted from [40].

\section{Overview of a wave energy project}

The project development process of a wave energy system may be represented as in Fig. 3. The process is iterative and includes complex interactions between the phases and/or sub-processes. However, these interactions are ignored in Fig. 3 for ease of comprehension. A wave energy project may be divided into two main processes: design and implementation. The former comprises preliminary design, detailed design, and model design and testing sub-processes. Preliminary design starts with the definition of WEC and PTO (Power Take-Off) concepts, the definition of the mathematical and numerical models, site data gathering and analysis up to validation of the models, either through reference problems or model testing. Detailed design requires the accomplishment of an optimisation phase followed by a performance assessment. Model design and testing may be transversal to both the preliminary design and the detailed design. It can be executed at different scales (small, medium and large-scale) to evaluate the performance of a WEC concept and tune the system components to achieve maximum efficiency and reliability.

The implementation process involves construction, deployment, operation \& maintenance, and decommissioning when the lifetime of the project is terminated. Each of these should be followed by continuous monitoring and control.

This work focuses on the model design and testing sub-process, which is of utmost importance to recreate the main characteristics and similarities among different scales for a given design. The process approach, presented in this work, is based on experience and best practices of the authors and research teams.

\subsection{Model design and testing}

Model design and testing is a mandatory phase within any wave energy project development. WECs are complex systems that differ from conventional offshore structures, and this is also reflected in the model design and testing process. Some of the differences are associated with the working principle and their power take-off systems (PTOs), which may create inherent conflicts when dealing with similarity require- ments for a successful emulation of the system, especially at small- and medium-scale testing.

The model design sub-process comprises the conception of the physical model for testing (see Fig. 4). It starts with the data associated with the full-scale technology and the conception of the idealised model, commonly performed with the aid of CAD tools. Afterwards, the idealised model is transformed into a realisable model, considering both model design properties and targets (see Fig. 5), and the characteristic and properties of real parts and components. Geometry, mass and volume are interlinked properties that should be handled iteratively to get the target variables as close as possible to the idealised model. The relationships between these target variables are complex. For example, the submerged volume affects the centre of buoyancy $(\mathrm{CoB})$, but also the mass, the centre of mass (CoM), the moment of inertia and the 


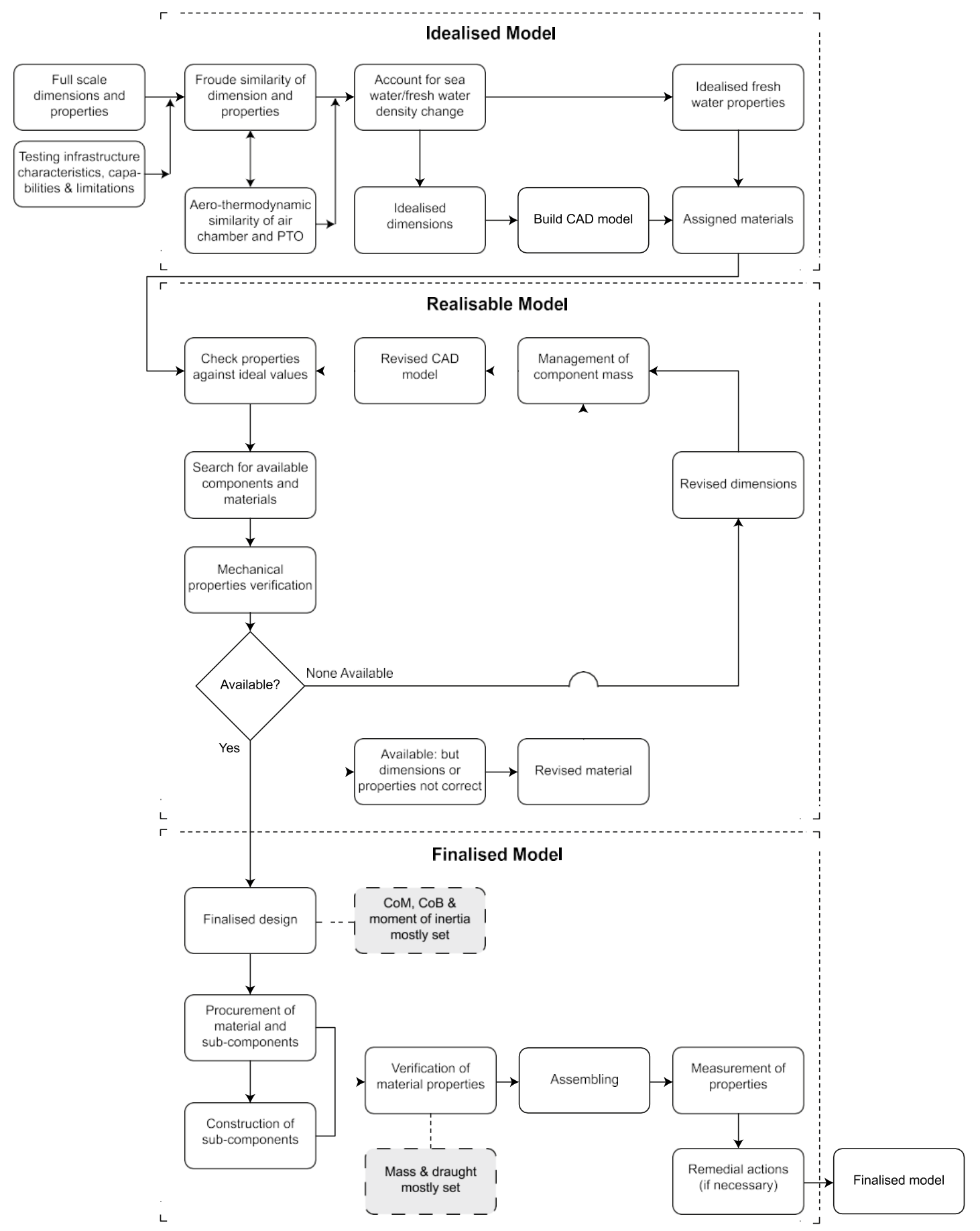

Fig. 4. Model design sub-processes for wave energy technologies.

draught. The finalised model is then the actual model constructed and verified, including any remedial actions, if required.

The model testing sub-process requires as inputs the data of the fullscale and model-scale designs, as well as the physical model (see Fig. 6). Model test planning is of utmost importance to avoid unnec- essary extra costs and delays on the testing campaign. It should be emphasised here that model test planning and model design should be developed interactively. Experience is a requirement to identify and manage assertively potential risks. Infrastructure, materials and equipment involved are generally expensive and require sophisticated skills to manage, and they should be wisely selected. Data collection, postprocessing, analysis and comparison are, of course, important to evaluate the overall project feasibility.
There is no clear consensus on what should be the different scales for testing. These depend, certainly, on the specific technology, costs, availability of test facilities/infrastructure, and other resources required to accomplish the purpose of the tests. Refs. [1,10,12] provide additional information. Scales range from 1:100-1:40 in small-scale models, 1:40-1:20 in medium-scale models, 1:20-1:4 in large-scale models, and 1:4-1:1 in prototypes.

\subsection{Essential steps in experimental campaigns of wave energy converters}

Essential steps associated with the development of wave energy converter experimental tests are identified as: 


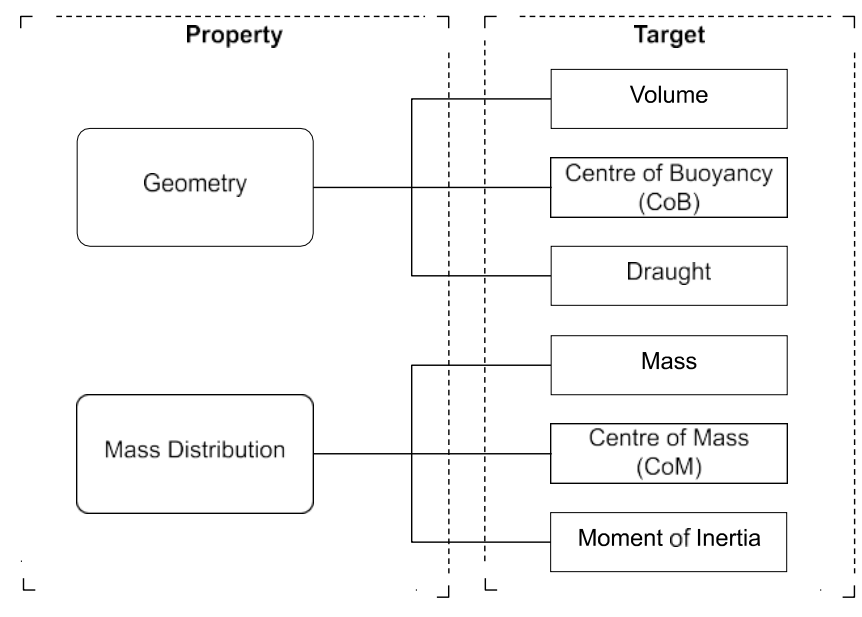

Fig. 5. Model design properties for wave energy technologies.

- objective definition;

- environmental conditions definition;

- scale ratio and physical similarity definition;

- testing infrastructure selection;

- tests definition;

- instrumentation plan definition and procurement;

- model design, construction and verification of properties;

- model testing;

- data preservation/storage, processing and reporting;

- learned lessons for future tests.

Once again, it should be evident to the reader that most of the steps above are interlinked, and some of them should be considered simultaneously at some point. For example, the definition of the scale ratio, testing infrastructure selection, tests definition and the instrumentation plan should be all considered together; however, they are at the same time different steps. Furthermore, in this work, it is considered that PTOs and moorings form part of the device design, and consequently, they are scaled or emulated within the model design and testing sub- process. For additional guidance, environmental conditions, and tests definition, see Refs. [11,12].

\subsection{Common issues in physical modelling of oscillating-water-column WECs}

\subsubsection{Physical model similarities}

Models and full-scale designs should be similar in terms of geometry, kinematics and dynamics, i.e. there must be a similitude of the shape for both the WEC and the surroundings (geometrical similarities), the velocities that imply both the flow and the model to have similar geometrical movements (kinematic similarity), and forces (dynamic similarity). If geometric and dynamic similarities are achieved, then the kinematic ones are also met.

Dynamic similarity implies that the ratio of representative forces is the same in both the model-scale and the full-scale. Most common dimensionless numbers associated with WEC devices, structures and their components, are the Froude number (Fr), the Reynolds number $(\mathrm{Re})$, the Keulegan-Carpenter number (KC), and the Strouhal number (St) $[41,42]$. The Froude number represents the ratio between inertia and gravity forces. The Reynolds number is the ratio between the inertia and viscous forces. The Keulegan-Carpenter number expresses the ratio between the drag and the inertia forces and is used to identify if a phenomenon is more drag or inertia dominated, giving orientations on the suitability of the mathematical models used and the respective assumptions. The Strouhal number describes the ratio be- tween temporal inertial forces and convective inertial forces; it should be considered for oscillatory flows and moving structures with flow
Table 1

Scaling factors for physical modelling of OWCs. $\square$ is defined as the physical model scale

\begin{tabular}{|c|c|c|c|}
\hline Physical parameter & Unit & Scaling factor & Scaling criterion \\
\hline Length & {$[\mathrm{m}]$} & $\square$ & Froude \\
\hline Time & [s] & $\square^{0.5}$ & Froude \\
\hline Mass & {$[\mathrm{kg}]$} & $\square^{3}(\square-F)$ & Froude \\
\hline Acceleration & {$\left[\mathrm{m} / \mathrm{s}^{2}\right]$} & 1 & Froude \\
\hline Force & {$[\mathrm{N}]$} & $\square^{3}(\square \square F)$ & Froude \\
\hline Torque & {$[\mathrm{Nm}]$} & $\square^{4}(\square \square F)$ & Froude \\
\hline Power & {$[\mathrm{W}]$} & $\square^{3.5}(\square \mathrm{F})$ & Froude \\
\hline Pressure & {$[\mathrm{Pa}]$} & $\square\left(\square \pitchfork \sigma_{F}\right)$ & Froude \\
\hline Air chamber volume & {$\left[\mathrm{m}^{3}\right]$} & $\square^{2}(\square F)^{-1}$ (see Ref. [3]) & Compressibility \\
\hline
\end{tabular}

separation (vortex shedding). There are other effects on OWCs such as the spring-like air compressibility in the air chamber (not related to Mach number) $[9,38,43]$.

\section{Reynolds number effect correction}

Similarity conditions in physical model testing of WECs require the equality of both the Froude number and the Reynolds number. In practice, this is not possible if the tests are performed in water [3]. It is widely acknowledged that the Froude criterion should prevail [41]. If this is adopted, the Reynolds number is smaller in the model, and the viscous effects are over-simulated. A correction to that may be introduced through the use of the Morison's equation [44].

PTOs and compressibility effects in physical modelling of OWCs: an important similarity challenge

Scaling down an OWC WEC has a specific set of challenges. The coupling between the hydrodynamics of the wave energy absorption and the turbine-generator set is done through the air chamber, which itself introduces additional similarity issues. The correct simulation of the spring-like air compressibility effect requires the volume of the air chamber to be scaled as the square, not the cube, of the length scale $[3,38]$. This may be done in practice by connecting the model air chamber to a rigid-walled reservoir of appropriate volume. In floating devices, this may raise problems if the dynamics of the structure is not to be affected. Failure to correctly scale the volume of the air chamber may introduce substantial errors in the capture width ratio $[38,45]$.

Depending on the geometric model scale, it might be infeasible to build a small-scale air turbine that complies with the geometric and dynamic similarities [38]. Turbine simulators must be used for scales lower than 1:4 [3]. Wells turbines are simulated using porous media where the flow rate exhibits a linear relationship with the pressure (the flow is laminar). In the case of impulse turbines, an orifice is used to simulate a quadratic relationship between the pressure and the flow rate (the flow is a jet).

Table 1 presents the scaling factors for some quantities in OWCs, where $\square$ represents the ratio of characteristic lengths between the model-scale, $\square_{M}$, and the full-scale, $\square_{F}$, i.e., $\square=\square_{F}$. The water densities at model-scale and full-scale are denoted as $\square_{M}$ and $\square_{F}$, respectively.

\subsubsection{Model verification}

Model verification is an iterative task for both model design and the model testing sub-processes. Once the ideal model is established from the real design, it becomes the reference to be achieved. Nevertheless, most of the time to ensure complete similitude is not possible. Realisable models depend on the availability of the right materials, components, and also the facility where it will be tested. The latter needs special considerations due to possible limitations of the testing tank or site that may impose additional conflicts, requiring further remedial actions.

This recursive task does not stop with the verification of the constructed model's properties, instead it continues into the testing period due to the possibility of variation in properties of the assembly. An 


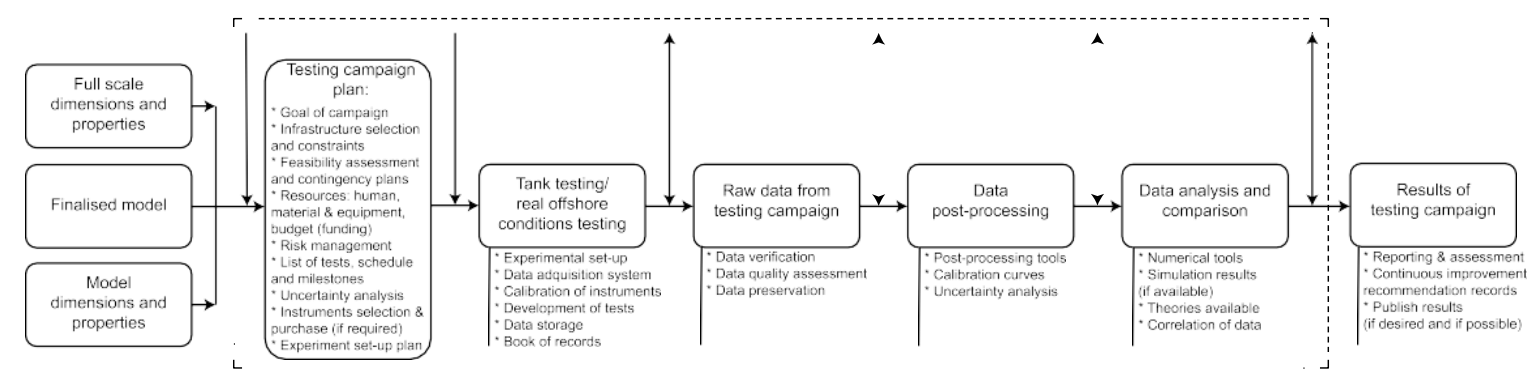

Fig. 6. Model testing sub-processes for wave energy technologies.

example of the latter may be an infiltration of water to the WEC model that would change the draught, and consequently, depending on the magnitude of the issue, its dynamics. It is highlighted the need of continuous observation of the main characteristics of the experimental set-up, which can change from day to day with the potential of invalidating results. Some indicators might help to control potential changes in designed conditions.

\subsubsection{Remedial actions}

Remedial actions are commonly required when dealing with physical model testing of WECs. It is recommended to establish a set of maximum deviation limits in model design properties, according with the specific objectives of the testing campaign, which can serve as a reference when making decisions on remedial actions. These actions vary from corrections in the centre of mass or buoyancy, mass distribution (due to imperfections in material/components, for example), draught (due to infiltrations or leakages, for example), and also measuring sensors/equipment (due to position/selection/replacement/weight of sensors/equipment). These are just examples of common actions that may be required to ensure a better similarity of the model and a better 'operational' model testing deployment.

\subsubsection{Physical model testing costs}

Physical model testing costs are generally high. Careful selection of infrastructure, planning, scheduling and control is necessary for a successful testing campaign. Infrastructure access is one of the highest costs in model testing. These costs depend on the size and type of infrastructure. The infrastructures can be classified as small- and medium-scale wave tanks/flumes, as well as medium- and large-scale test sites. The first two provide controlled environments that may recreate regular and irregular waves. Test sites offer realistic deployments, without control over the environmental conditions.

Besides the infrastructure selection, testing duration and measurement equipment are crucial to estimate total costs associated with any campaign. Depending on the target facility, measurement equipment may be available for extra fees or even included in the service package price. Technical support and other services may be available, such as post-processing of data and analysis of results. The larger the tank, the higher the costs associated. Nevertheless, cost estimation is difficult and depends strongly on the needs, the facility, special requirements, and the contracting organisation. Testing costs may reach tens of thousands of euros per week.

Costs such as model construction, transportation, measuring instruments, and travel expenses may be substantial, depending on the scale and size of the model, distance to infrastructure, testing campaign time, measurement and technical support needed. It is not an easy task to make proper cost estimations, and significant deviations in budget happen frequently. A critical recommendation to avoid unnecessary delays is to visit the tank or facility in advance and work together with the infrastructure manager to get realistic plans and ensure a smoother process.

\section{Coaxial-duct and spar-buoy OWCs physical model testing}

\subsection{Objectives \& methods}

The objective of the testing campaign at the COAST Laboratory of the University of Plymouth (UoP) was to characterise and study the performance and loads on mooring lines of two physical models at scale 1:40: a coaxial-duct and a spar-buoy OWC WECs. Experiments were performed during three experimental campaigns: October 2015, December 2015-January 2016, and July 2017.

The experimental work comprised regular and irregular wave test conditions, as well as extreme wave conditions. Regular-wave tests

were used to examine devices' capture width ratio at specific frequencies and the displacement RAOs, while irregular-wave tests were used to examine performance in terms of capture width ratio. Highly

energetic sea states were used to provide data on device motions and tensions in mooring lines under extreme conditions. These highly energetic sea states were based on the wave climate encountered at Leixões, Portugal, see Table 2 . The survivability waves represented the 10-, 50- and 100-year return periods based on the same spectral shape.

Data were collected from four different types of instruments: wave resistive probes, pressure sensors, load cells and from a six degrees

of freedom (6-DoF) motion tracking system, along with four digital video cameras positioned both above and below the water. For the experimental campaigns, data acquisition was synchronised between the various systems.

The load cells were calibrated by the supply company, and the maximum total error was within $\pm 0.01 \%$ of full span. An uncertainty analysis on the measurements was performed. Wave gauges were calibrated daily, and gave error typically less than $\pm 1.6 \%$ of total measurement span $(0.6 \mathrm{~m})$; while pressure sensors total error band was $\pm 1 \%$ of the full-scale span based on data sheet of sensor. On what concerns the 6DoF motion tracking system used to measure instantaneous positions, the measuring errors are given in the cameras output files per record.

\subsection{Testing infrastructure}

The choice of the physical modelling scale was linked to the size of the wave basin. The Ocean Basin is a deep-water wave and current facility. It has nominal dimensions of $15.5 \mathrm{~m}$ wide and $35 \mathrm{~m}$ long (Fig. 7). The central floor section of the basin may be fixed at any position from the surface down to $3 \mathrm{~m}$ depth. The basin is equipped with 24 flaptype paddles with a hinge depth of $2 \mathrm{~m}$. The wave files are created with the Njord Wave Synthesis program and are generated by a control software. Irregular waves followed a Pierson-Moskowitz spectrum.

\subsection{Physical models and configuration}

Two WEC devices were used to investigate the performance and survivability: the coaxial-duct OWC (CD-OWC) and the spar-buoy OWC $[46,47]$. The 1:40-scale models were designed based on a full-scale design $[48,49]$. They were designed and manufactured at UoP, following 


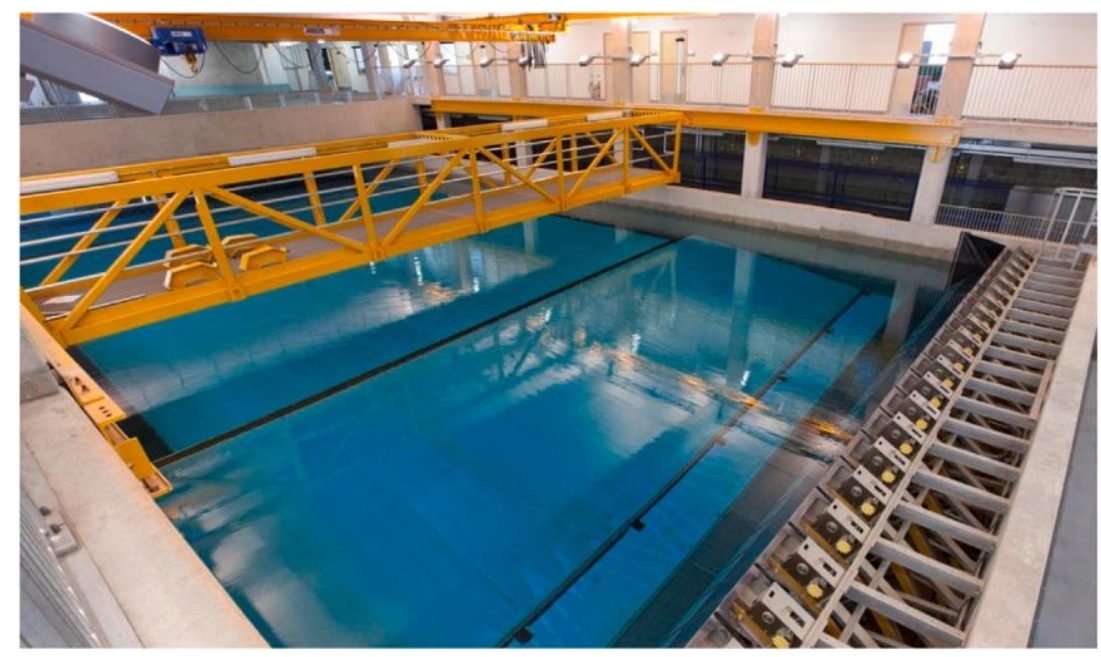

Fig. 7. View of the ocean basin at COAST Lab., University of Plymouth.

Table 2

Scatter plot of probabilities of occurrence for the most representative sea states off Leixões, Portugal. Source: Adapted from Ref. [46].

\begin{tabular}{lllllllllllll}
\hline$\square_{\mathrm{s}}[\mathrm{m}]$ & $\square_{\mathrm{e}}[\mathrm{s}]$ & & & & & & & & & & & $P\left[\square_{\mathrm{s}}\right]$ \\
& $4-5$ & $5-6$ & $6-7$ & $7-8$ & $8-9$ & $9-10$ & $10-11$ & $11-12$ & $12-13$ & $13-14$ & $(\%)$ \\
\hline $0.5-1$ & 0.07 & 2.41 & 2.21 & 0.33 & 0.01 & & & & & & 5.06 \\
$1-1.5$ & 0.03 & 4.53 & 10.14 & 5.8 & 2.03 & 0.38 & 0.05 & 0.01 & & & 23.11 \\
$1.5-2$ & & 1.73 & 7.04 & 7.22 & 5.39 & 2.29 & 0.34 & 0.12 & & & 24.28 \\
$2-2.5$ & & 0.23 & 2.57 & 3.77 & 4.28 & 3.78 & 1.77 & 0.41 & 0.05 & & 16.98 \\
& & & & & & & & & & & \\
$2.5-3$ & & & 0.59 & 2.01 & 2.82 & 2.52 & 1.88 & 0.71 & 0.13 & 0.01 & 10.74 \\
$3-3.5$ & & & 0.03 & 0.99 & 1.74 & 1.77 & 1.35 & 0.52 & 0.23 & 0.05 & 6.72 \\
$3.5-4$ & & & & 0.18 & 1.05 & 1.43 & 1.12 & 0.7 & 0.16 & 0.06 & 4.73 \\
$4-4.5$ & & & & 0.01 & 0.53 & 0.83 & 0.75 & 0.51 & 0.22 & 0.08 & 2.96 \\
$4.5-5$ & & & & & 0.11 & 0.60 & 0.70 & 0.55 & 0.29 & 0.10 & 2.38 \\
$5-6$ & & & & & & 0.36 & 0.83 & 0.61 & 0.33 & 0.07 & 2.23 \\
$6-7$ & & & & & & & 0.17 & 0.34 & 0.18 & 0.06 & 0.80 \\
\hline $\mathrm{P}\left[\square_{\mathrm{e}}\right](\%)$ & 0.10 & 8.92 & 22.61 & 20.35 & 18.00 & 13.99 & 9.01 & 4.59 & 1.80 & 0.64 & \\
\hline
\end{tabular}

Table 3

Physical properties of the full-scale, idealised 1:40-scale and constructed model of the CD-OWC. $\square$ represents the total height, $\square_{\mathrm{D}}$ is the draught, and $\square_{0}$ the overlapping length of the coaxial tubes. $\square_{0}$ and $\square_{i}$ represent the external and internal diameters of the totally submerged tube, respectively, while $\square_{0}$ and $\square_{i}$ represent the external and internal diameters of the inner tube.

\begin{tabular}{lllll}
\hline Parameter & Full-scale & Idealised $1: 40$-scale & CAD model & Physical test model \\
\hline$\square[\mathrm{m}]$ & 43.0 & 1.075 & 1.075 & 1.085 \\
$\square \mathrm{D}[\mathrm{m}]$ & 33.0 & 0.825 & 0.825 & $0.810-0.910$ \\
$\square_{0}[\mathrm{~m}]$ & 13.0 & 0.325 & 0.325 & 0.325 \\
$\square$ o $[\mathrm{m}]$ & 14.0 & 0.350 & 0.340 & 0.340 \\
$\square[\mathrm{m}]$ & 12.0 & 0.300 & 0.300 & 0.300 \\
$\square$ o $[\mathrm{m}]$ & 9.2 & 0.230 & 0.215 & 0.223 \\
$\square_{i}[\mathrm{~m}]$ & 8.2 & 0.205 & 0.200 & 0.200 \\
$\square[\mathrm{kg}]$ & $1.818 \times 10^{6}$ & 28.4 & 28.4 & 28.8 \\
$\square\left[\mathrm{kg} \mathrm{m} \mathrm{m}^{2}\right]$ & $288.1 \times 10^{6}$ & 2.8 & 2.8 & n.d. \\
CoB to MWL $[\mathrm{m}]$ & 22.6 & 0.565 & 0.568 & n.d. \\
CoM to MWL $[\mathrm{m}]$ & 26.3 & 0.657 & 0.657 & 0.657 \\
\hline
\end{tabular}

the sub-process presented in Fig. 4. Several iterations of each design were used since the general properties were interlinked (see also Fig. 5). For example, the geometry determined the centre of buoyancy $(\mathrm{CoB})$ and affected the volume, ultimately affecting the draught.

The same 1:40-scale was applied to whole device. The spring-like air compressibility effects were not accounted for. The turbine damping was simulated by an orifice plate located at the top of each air chamber.

At each stage of the model design sub-process, there was a compromise between accuracy and simplicity. For example, published values of properties of materials were assumed to be correct, and dimensions were assumed to be realisable in manufacturing. Furthermore, fixings were not all accounted for in the CAD model, although their mass was not negligible. This explained deviations that appeared in the final model. A changeable ballast was considered in the model design to account for those differences $[46,47]$.

The main drivers for the model design were the relationship between the mass, geometry and material density. These determined the draught and the mass distribution, as well as the moments of inertia. The mass specification of the device, i.e., CoM location and the moment of inertia, were given priority.

The main problem of the preliminary design was the selection of the materials. The models could not be made of steel as full-scale device, as this would lead to excessively thin wall sections. With the constraint of a minimum wall thickness of $2 \mathrm{~mm}$, based on available materials and welding considerations, the mass of the model would be too large if only made of aluminium. This led to a design that used both aluminium 


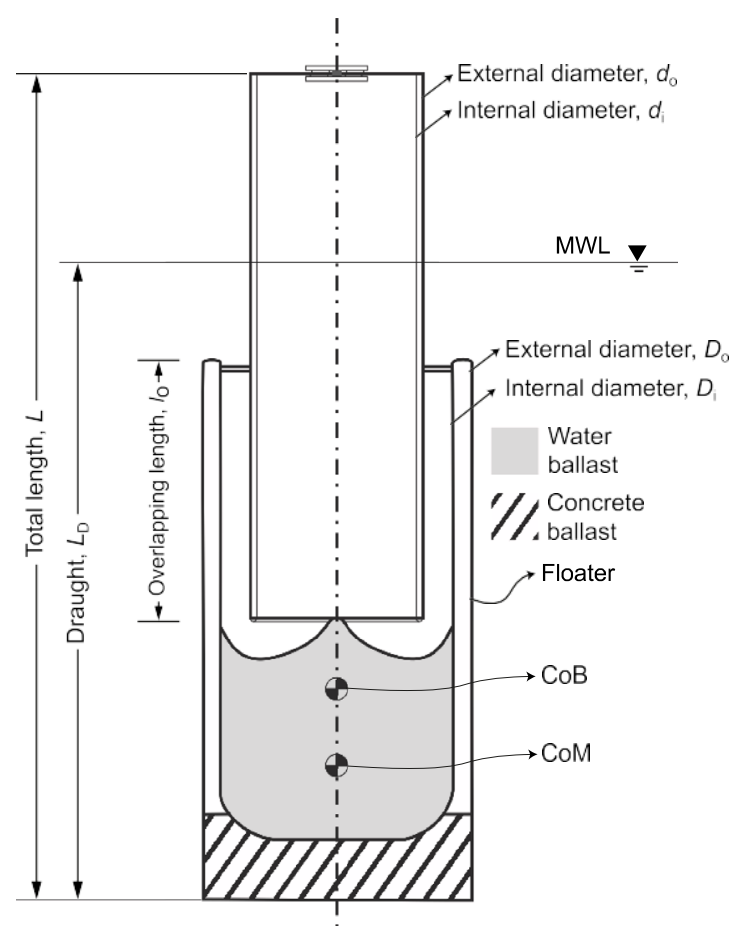

Fig. 8. Main characteristics of the CD-OWC device: cross section view without antiheave plate.

and acrylic. The second design condition was the correct draught in fresh water.

Model design should allow several configurations. This had to be considered at an early stage to avoid delays and extra costs.

\subsubsection{Coaxial-duct $O W C$}

The CD-OWC consists of two coaxial, partially overlapping cylindrical tubes, forming an inner and an outer duct, see Fig. 8. The crosssectional area of the inner duct is equal to the annular area of the outer duct. The cylindrical walls are hollow for buoyancy reasons. The two shaded areas in Fig. 8 are filled to provide ballast and to lower the CoM. The outer cylindrical wall is fully submerged whereas the inner cylindrical wall extends above the free surface to provide connection to the air turbine. The two ducts are inter-connected at their bottom and form an axisymmetric OWC with an upward-facing connection to the water surrounding converter. The water plane area is equal to the cross sectional area of the inner tube. Since this area is relatively small, the floater behaves in waves as a semi-submersible structure, and so the resonance frequency of the heave oscillations may be designed to be smaller than the typical frequencies of the incident wave spectra. If this is the case, the heave oscillation amplitudes are expected to be small. Unlike the spar-buoy OWC, the energy absorption results essentially from the interaction between the waves and the OWC motion, rather than the waves and the floating structure.

The connection between the two ducts has a smooth shape to reduce hydrodynamics losses, see Fig. 8. An anti-heave plate was attached to the device for the testing campaign, see Fig. 9. Comparisons between the full-scale and model-scale properties are shown in Table 3.

Four catenary mooring lines were used to keep the device in station. These were placed orthogonally to each other, approximately coincident with the CoM in the $\square$-direction (vertical direction). The model was moored such that the axis of symmetry of the device was coincident with the centre of the basin. Anchor points radiated $6 \mathrm{~m}$ from the basin centre. The mooring lines properties are summarised in Tables 4 and 5. The turbine simulator was an orifice with a diameter of $30 \mathrm{~mm}$ on the top wall of the model's air chamber.
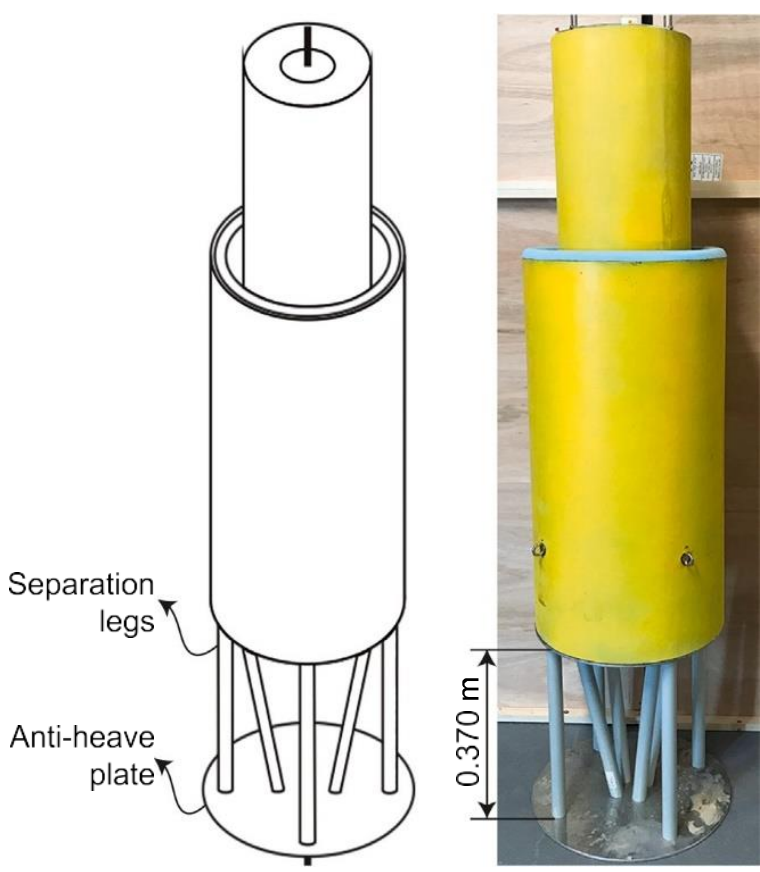

Fig. 9. The CD-OWC CAD and constructed models with a $0.375 \mathrm{~m}$ diameter anti-heave plate placed at $0.370 \mathrm{~m}$ from the model bottom through eight separation legs.

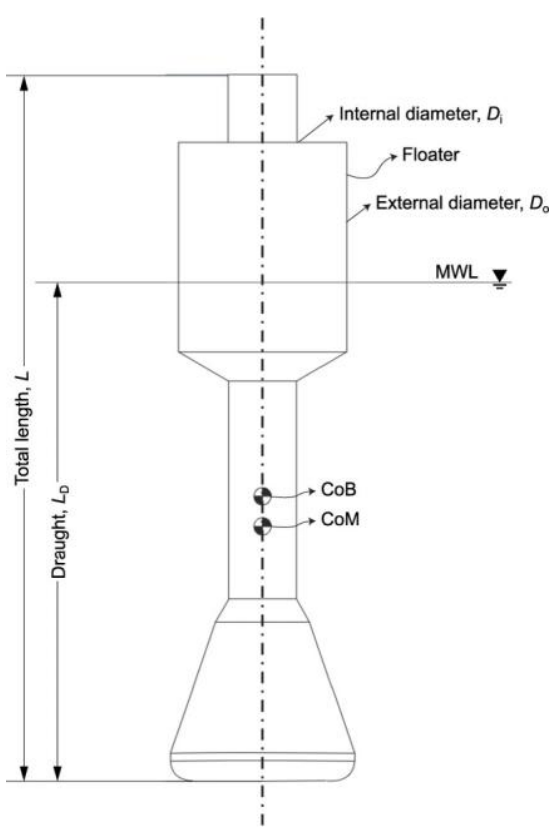

Fig. 10. The spar-buoy OWC model representation with indication of the main characteristics.

\subsubsection{Spar-buoy $O W C$}

The full-scale WEC has $12 \mathrm{~m}$ diameter at free surface level and a draught of $36 \mathrm{~m}$, see Fig. 10 [46,48]. The model was built at a scale of 1:40. The properties of the full-scale and model-scale buoy are shown in Table 6. Fig. 11 presents a CAD drawing and a photograph of the finished model. The device was approximately $1.25 \mathrm{~m}$ high, with a mass of $19.0 \mathrm{~kg}$. 
Table 4
Physical properties of the full-scale and idealised 1:40-scale model of mooring lines for the CD-OWC

\begin{tabular}{lll}
\hline Parameter & Full-scale & Idealised 1:40-scale \\
\hline Number of lines & 4 & 4 \\
Number of vertical mooring line segments & 1 & 1 \\
Water depth [m] & 80 & 2 \\
Chain type & Studlink & Studlink \\
Chain diameter [mm] & 80 & 2 \\
Chain total dry mass [kg] & 31193 & 0.487 \\
Length of chain [m] & 255 & 6.375 \\
Mooring radius (from device axis to anchor) [m] & 240 & 6 \\
Fairlead position for line 1 [m] & $(4.95,4.95,-26.00)$ & $(0.12,0.12,-0.65)$ \\
Fairlead position for line 2 [m] & $(-4.95,4.95,-26.00)$ & $(-0.12,0.12,-0.65)$ \\
Fairlead position for line 3[m] & $(-4.95,-4.95,-26.00)$ & $(-0.12,-0.12,-0.65)$ \\
Fairlead position for line 4 [m] & $(4.95,-4.95,-26.00)$ & $(0.12,-0.12,-0.65)$ \\
Bottom anchor position for line 1 [m] & $(169.71,169.71,-80.00)$ & $(4.24,4.24,-2.00)$ \\
Bottom anchor position for line 2[m] & $(-169.71,169.71,-80.00)$ & $(-4.24,4.24,-2.00)$ \\
Bottom anchor position for line 3[m] & $(-169.71,-169.71,-80.00)$ & $(-4.24,-4.24,-2.00)$ \\
Bottom anchor position for line 4[m] & $(169.71,-169.71,-80.00)$ & $(4.24,-4.24,-2.00)$ \\
\hline
\end{tabular}

Table 5

Properties of mooring lines for the idealised 1:40-scale and constructed models of the $\underline{C D-}$ OWC

Mooring line Target length $[\mathrm{m}]$ Measured length $[\mathrm{m}]$ Measured dry mass [kg]

\begin{tabular}{llll}
1 & 6.367 & 6.370 & 0.452 \\
2 & 6.367 & 6.374 & 0.452 \\
3 & 6.367 & 6.368 & 0.452 \\
4 & 6.367 & 6.375 & 0.454 \\
\hline
\end{tabular}
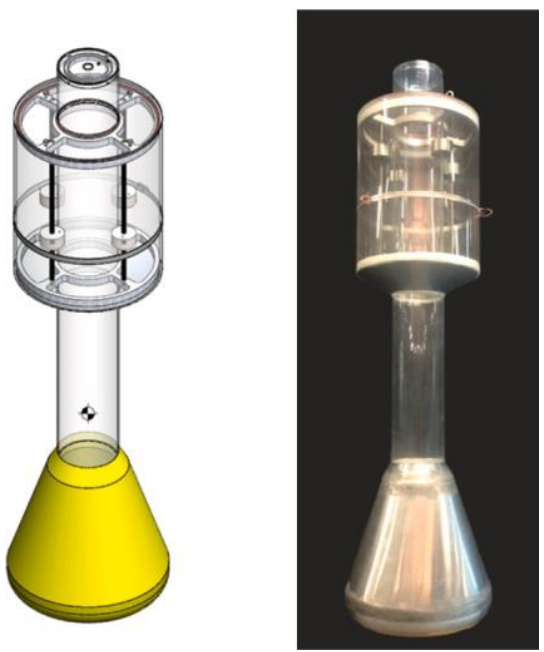

Fig. 11. The spar-buoy OWC CAD and constructed models.

The device had three mooring lines. The lines were connected to the basin floor, and were composed of chains, synthetic lines with floats and clump weights. Synthetic lines were tied to chains and to fairleads or load cells, where appropriate. Details of the lines, floats and clump weights are given in Tables 7 and 8. The PTO was implemented through an orifice plate of $17.5 \mathrm{~mm}$ diameter, which was placed at the top of the model air chamber.

\subsection{Verification and deviation from the design specification}

Verifications were done at different stages, after material reception, after fabrication of parts, when the models were assembled, and during tests execution. Besides internal factors, there were also important external factors to consider. For example, during the fabrication of the spar-buoy, some parts were fabricated in-house, and others through sub-contractors. Once parts were delivered, it was realised that the of models, different joint and isolation methods were implemented, thickness of the plates were larger than specified. In the assembling 
sGch Pastibeallalnts, bolting, welding and bonding, which represented an addition of mass that was not accounted for. In these processes, the additional mass of bobleqing material and paint contributed to deviations from the designed models.

Models were checked for mass, unmoored draught, location of the CoM and mass moment of inertia. The difference in the mass of the idealised 1:40-scale model and the CAD model was due mainly to the change in geometry necessary to achieve the desired draught with commercially available components. Each parameter was given an acceptable range of values as follows:

- Mass: $\pm 5 \%$ with respect to CAD model.

- CoM location: $\pm 5 \%$ with respect to base of idealised model.

- $\square_{\square 口}: \pm 20 \%$ with respect to idealised model.

- Lengths of the device: $\pm 5 \mathrm{~mm}$ was used for the remaining length scales of the device.

- Mooring lengths: $\pm 10 \mathrm{~mm}$.

3.4.1. Mass and unmoored draught

The mass of the models was measured using laboratory scales without the instrumentation. To measure the unmoored draughts, the models were allowed to float in the University of Plymouth Ocean Basin with the floor at $3 \mathrm{~m}$ depth. The waterline of the free floating unmoored devices was marked on one side of the top floater section. This was difficult to achieve as any movement of the water caused the model to move in several of its degrees of freedom. The estimated error associated with the measurement process was $\pm 2 \mathrm{~mm}$ owing to the water (and model) movement and the accuracy of identifying the true waterline. Graduated scales on floaters and photographic records were used to reduce measurement errors.

\subsubsection{Centre of mass and inertial properties}

The spar-buoy CoM was determined suspending the device horizon- tally by two stiff vertical lines equipped with load cells to measure forces. The MWL-CoM distance was found to be $475 \mathrm{~mm}$ using the static equilibrium of moments. A similar procedure was followed for the CD-OWC, but in this case the device was not suspended, it wasplaced on a rack prepared with two load cells. The MWL-CoM distance was determined as $635 \mathrm{~mm}$ in this case.

The methodology set out in Ref. [50] was adopted to measure the mass moment of inertia of the spar-buoy OWC model. The model was suspended from a pivot and allowed to oscillate as a gravitational pendulum. The angular displacement of the device was recorded using a 6-DoF motion tracking system to determine the average swing period. This period was later used to estimate the moment of inertia. The method is very sensitive to the vertical distance of the CoM. It was found that a small difference of $2 \%$ in the measurement of the CoM 
Table 6

Physical properties of the full-scale idealised 1:40-scale and constructed models of the spar-buoy OWC. $\square$ represents the total length, $\square_{D}$ is the draught, while $\square_{0}$ and $\square_{i}$ represent the outer diameter of the floater and the internal diameter of the central tube and floater, respectively.

\begin{tabular}{lllll}
\hline Parameter & Full-scale & Idealised 1:40-scale & CAD model & Physical test model \\
\hline$\square[\mathrm{m}]$ & 51.0 & 1.275 & 1.275 & 1.277 \\
$\square_{\mathrm{D}}[\mathrm{m}]$ & 36.0 & 0.900 & 0.900 & 0.900 \\
$\square_{\mathrm{o}}[\mathrm{m}]$ & 12.0 & 0.300 & 0.300 & 0.290 \\
$\square \mathrm{i}]$ & 4.8 & 0.120 & 0.119 & 0.119 \\
$\square[\mathrm{kg}]$ & $1.217 \times 10^{6}$ & 19.0 & 18.9 & 18.9 \\
$\square\left[\mathrm{kg} \mathrm{m}{ }^{2}\right]$ & $324.6 \times 10^{6}$ & 3.2 & 3.2 & 3.9 \\
CoB to MWL $[\mathrm{m}]$ & 18.0 & 0.451 & 0.451 & n.d. \\
CoM to MWL $[\mathrm{m}]$ & 19.3 & 0.482 & 0.482 & 0.470 \\
\hline
\end{tabular}

Table 7

Physical properties of the full-scale and idealised 1:40-scale model of mooring lines for the spar-buoy OWC.

\begin{tabular}{lll}
\hline Parameter & Full-scale & Idealised 1:40-scale \\
\hline Number of lines & 3 & 3 \\
Number of mooring line segments & 3 & 3 \\
Water depth [m] & 80 & 2 \\
Mooring radius (from device axis to anchor) [m] & 210 & 5.25 \\
Length of section 1 (Rope) [m] & 51.56 & 1.29 \\
Length of section 2 (Rope) [m] & 148.91 & 3.72 \\
Length of section 3 (Chain) [m] & 46.20 & 1.16 \\
Section 1 type & Spiral strand & Spiral strand \\
Section 2 type & Spiral strand & Spiral strand \\
Section 3 type & Chain studlink & Chain studlink \\
Rope diameter [mm] & 65 & 1.625 \\
Chain diameter [mm] & 180 & 4.5 \\
Chain total dry mass [kg] & 22605 & 0.353 \\
Number of floaters in section 2 & 6 & 6 \\
Position of floaters & $(69.77,71.21,72.65$, & $(1.74,1.78,1.82$, \\
$\quad$ along line (from fairlead) [m] & $74.09,75.53,76.97)$ & $1.85,1.89,1.92)$ \\
Float dry mass $[\mathrm{kg}]$ & 326.8 & $5.11 \times 10^{-3}$ \\
Float density [kg/m ${ }^{3}$ ] & 150 & 150 \\
Fairlead position for line 1 [m] & $(6.00,0.00,-0.03)$ & $(0.15,0.000,-0.001)$ \\
Fairlead position for line 2 [m] & $(-3.00,-5.20,-0.03)$ & $(-0.075,-0.130,-0.001)$ \\
Fairlead position for line 3 [m] & $(-3.00,5.20,-0.03)$ & $(-0.075,0.130,-0.001)$ \\
Bottom anchor position for line 1 [m] & $(210.00,0.00,-80.00)$ & $(5.25,0.00,-2.00)$ \\
Bottom anchor position for line 2[m] & $(-201.45,-348.92,-80.00)$ & $(-5.04,-8.72,-2.00)$ \\
Bottom anchor position for line 3[m] & $(-201.45,348.92,-80.00)$ & $(-5.04,8.72,-2.00)$ \\
\hline
\end{tabular}

Table 8

Properties of mooring lines for the idealised 1:40-scale and constructed models of the spar-buoy OWC.

\begin{tabular}{|c|c|c|c|c|c|c|}
\hline $\begin{array}{l}\text { Mooring } \\
\text { line }\end{array}$ & $\begin{array}{l}\text { Chain } \\
\text { length }[\mathrm{m}]\end{array}$ & $\begin{array}{l}\text { Fairlead to } \\
\text { Clump length [m] }\end{array}$ & $\begin{array}{l}\text { Total rope } \\
\text { length }[\mathrm{m}]\end{array}$ & $\begin{array}{l}\text { Total line } \\
\text { length }[\mathrm{m}]\end{array}$ & $\begin{array}{l}\text { Clump } \\
\text { mass }[\mathrm{kg}]\end{array}$ & $\begin{array}{l}\text { Floats } \\
\text { mass }[\mathrm{kg}]\end{array}$ \\
\hline Target & 1.155 & 1.289 & 5.012 & 6.167 & 1.807 & $6.5 \times 10^{-3}$ \\
\hline 1 & 1.126 & 1.256 & 4.955 & 6.081 & 1.806 & $6.5 \times 10^{-3}$ \\
\hline 2 & 1.173 & 1.285 & 4.965 & 6.138 & 1.808 & $6.5 \times 10^{-3}$ \\
\hline 3 & 1.173 & 1.310 & 4.980 & 6.153 & 1.807 & $6.5 \times 10^{-3}$ \\
\hline
\end{tabular}

vertical distance may represent up to a $30 \%$ difference in the value of the moment of inertia, $\square_{\square \square}$.

The moment of inertia of the CD-OWC model was estimated using the swinging carriage method described in [42]. The test rig comprised a carriage free to move around a pivot suspended from a rigid frame. A sequence of experiments was performed with the swinging carriage employing the model, a trim weight and the measurement of the tilt angles to calculate the moment of inertia.

\subsubsection{Centre of buoyancy}

CAD models of the buoys with uniform density were used to estimate the centre of buoyancy $(\mathrm{CoB})$ considering the design draught. Any deviation of the draught should be checked to estimate the effect of the $\mathrm{CoB}$ change on the system's performance.

\section{Results of physical model tests}

This section presents some of the results obtained from the experimental campaign. Results are focused on natural periods, capture width ratio (CWR), and displacements of the device.

\subsection{Natural periods}

Table 9 shows the mean values of the natural periods $\left(\square_{n}\right)$ obtained experimentally, based on the average of five tests, and the full-scale theoretical natural periods for the CD-OWC and the spar-buoy OWC. The decay tests showed very low standard deviation values, indicating good repeatability, despite the inherent difficulties in perturbing the device only along one axis. Presented results for surge, heave and pitch have a tolerance of $95 \%$ confidence interval to indicate the repeatability of testing in each degree of freedom.

Due to the axisymmetric design of the device, the planar translations (surge and sway) and rotations (roll and pitch) were very similar. Small differences in the results were due to the orientation of the mooring restoring forces with respect to the motion axis.

The natural frequency of the internal mass of water (water column) was not measured. Instead, theoretical full-scale natural periods were considered. In the case of the CD-OWC, the full-scale natural period is $11.69 \mathrm{~s}$, with a corresponding frequency at the 1:40-scale model of $0.541 \mathrm{~Hz}$. In the spar-buoy OWC, the natural period is $11.33 \mathrm{~s}$ for the full-scale design, which is equivalent to $0.558 \mathrm{~Hz}$ at $1: 40$-scale. 
Table 9

Natural periods for selected degrees of freedom (DoF) obtained theoretically and experimentally, through testing of the CD-OWC and spar-buoy OWC models.

\begin{tabular}{|c|c|c|c|c|c|c|}
\hline \multirow[t]{3}{*}{ DoF } & \multicolumn{3}{|l|}{ CD-OWC } & \multicolumn{3}{|c|}{ Spar-buoy OWC } \\
\hline & \multirow{2}{*}{$\begin{array}{l}\text { Theoretical } \\
\text { Full-scale }\end{array}$} & \multicolumn{2}{|l|}{ Experimental } & \multirow{2}{*}{$\begin{array}{l}\text { Theoretical } \\
\text { Model-scale }\end{array}$} & \multicolumn{2}{|l|}{ Experimental } \\
\hline & & Model-scale & Full-scale Full-scale & & Full-scale & \\
\hline Surge period [s] & 149.6 & 27.5 & 174.0 & 71.7 & 16.2 & 102.6 \\
\hline Pitch period [s] & 22.8 & 3.0 & 18.7 & 29.8 & 5.6 & 35.2 \\
\hline
\end{tabular}

\subsection{Capture width ratio}

Regular wave tests were performed to characterise the performance of the device in terms of capture width ratio (CWR) and response amplitude operators (RAOs) curves. The CWR shows the ratio between the time-averaged pneumatic power $(\square)$ and the time-averaged wave power per unit crest length $\left(\square_{w}\right)$, non-dimensionalised by the characteristic length of the device ( $\square$ ), as follows,

$$
\begin{aligned}
& \text { CWR }=\stackrel{\square \square}{\square} \text {, } \\
& \square \square_{\mathrm{w}} \quad \mathrm{v} \\
& \square=\square \square \square=\square \square \emptyset \text { d } \frac{\underline{2 \square \square}}{\square_{\text {air }}} \text {, }
\end{aligned}
$$

where $\quad \mathrm{u}$ is the measured pressure drop between the air-chamber and the atmosphere, with $\square_{\text {air }}$ assumed as $1.225 \mathrm{~kg} / \mathrm{m}^{3}, \square_{\text {o }}$ represents the orifice area of the upper air chamber's plate. In addition, $\square_{d}$ represents the discharge coefficient, which has a value of 0.69 , obtained through calibration of the orifice plates [46].

For regular waves, the incident wave power per unit crest length is computed as

$\square_{\mathrm{w}}={ }^{1} \square_{\mathrm{w}} \square \square^{2} \square_{\mathrm{g}}$,

$$
2 w
$$

where $\square_{w}$ is the density of water, $\square_{w}$ is the wave amplitude, and $\square_{g}$ is the group velocity [51].

The capture width for the CD-OWC was non-dimensionalised by the diameter of the outer tube $\square=0.34 \mathrm{~m}$, while for the spar-buoy OWC the floater diameter $\square=0.30 \mathrm{~m}$ was used. The incident wave power, $\square_{\mathrm{w}}$, was computed for the incident regular wave conditions recorded during an extra set of tests performed without the devices. This was done with a water level gauge located where the devices would later be deployed.

Fig. 12 shows the capture width ratio for both the coaxial-duct and the spar-buoy OWCs with a wave height $\square=0.05 \mathrm{~m}$. For the spar-buoy, the curve of CWR versus frequency has a peak at $\square=0.620 \mathrm{~Hz}$. Close to the right of the peak, at $\square=0.630 \mathrm{~Hz}$ there is efficiency drop that may be explained by the occurrence of cross-waves observed in the basin.

Cross waves had already been observed in the basin as reported in Ref. [52]. They occurred when the basin width is a multiple of half wavelength, namely for frequencies $0.38,0.44,0.63$ and $0.97 \mathrm{~Hz}$ [52]. Cross waves of frequency $0.63 \mathrm{~Hz}$ were visible in the basin free surface for several minutes after the wavemaker shutdown. Cross waves were also found to occur in irregular waves, but it is difficult to predict their effects on the converter performance [52]. The limited width of the wave tanks makes the occurrence of cross waves difficult to avoid. This effect was also studied experimentally at a smaller scale model of the spar-buoy OWC [23].

The power output of both devices was negligible outside the frequency range $0.450<\square<0.900 \mathrm{~Hz}$. Close to the water column natural frequency $\square=0.550 \mathrm{~Hz}$ local peaks are seen to occur, see Fig. 12. The effect of the cross waves was detected in the RAOs.

\subsubsection{Capture width ratio as affected by the vertical position of the $C D$ - OWC in water}

A very small crack was detected in the bottom part of the CD-OWC model, which caused some water intrusion and a gradual increase in the

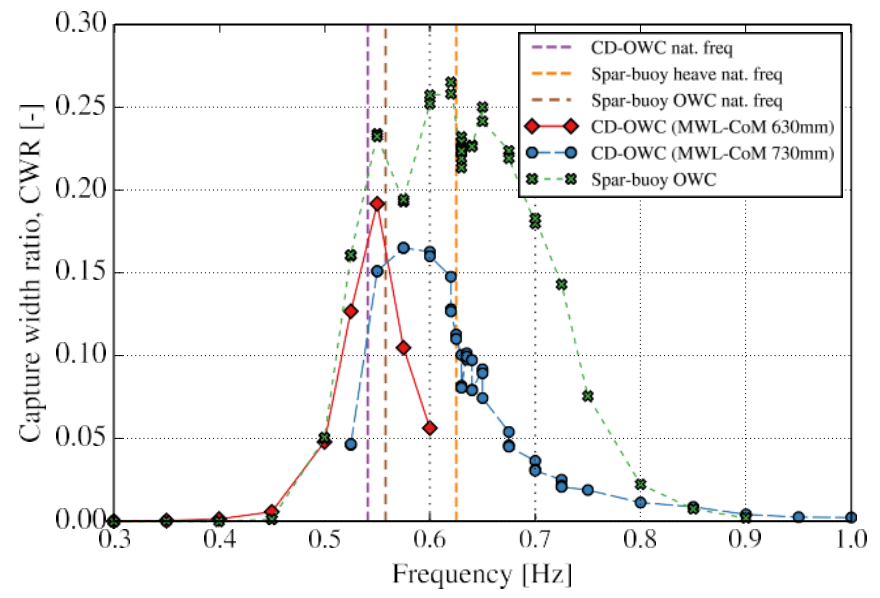

Fig. 12. Capture width ratio for both coaxial-duct and spar-buoy OWCs for regular waves with $\square=0.05 \mathrm{~m}$

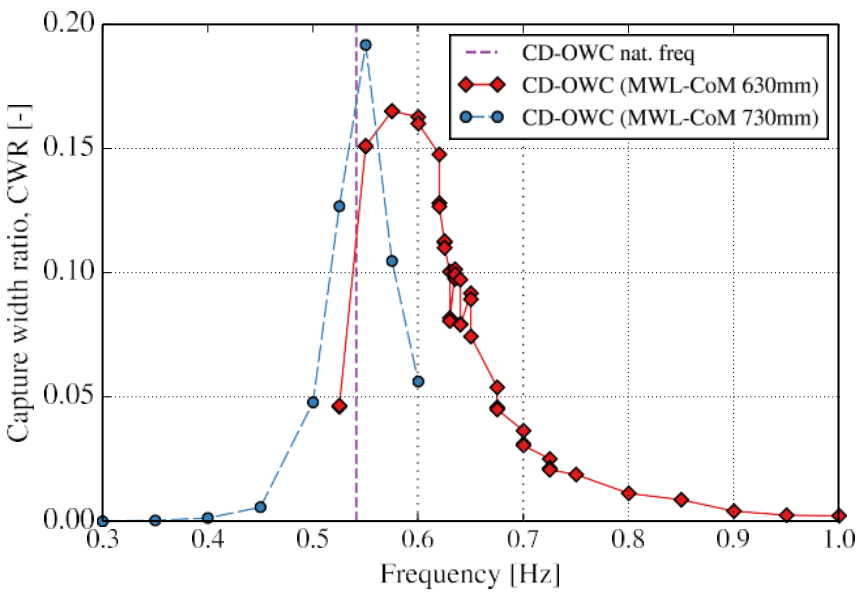

Fig. 13. Capture width ratios for the coaxial-duct OWC in regular waves with $\square=$ $0.05 \mathrm{~m}$ and different frequencies. Series are separated by experimental day with marker colour denoting MWL-CoM distance.

draught during the experiments. This effect was used to investigate how the CWR was affected by changes in the draught. Since the CD-OWC behaves as a semi-submersible device, the draught is very sensitive to small changes in its mass. In the following subsections, this issue is discussed.

Generally, there is a peak in the CWR between $\square=0.500$ and 0.600 $\mathrm{Hz}$, and a drop in the CWR for $\square=0.630$ and $0.640 \mathrm{~Hz}$ for two of the three experiments. Fig. 13 gives an indication of the performance in terms of the draught. When the MWL-CoM distance was about $730 \mathrm{~mm}$, the CWR peaked at $\square=0.550 \mathrm{~Hz}$ and the curve is narrow. With a MWLCoM distance of around $630 \mathrm{~mm}$, the peak of the capture width ratio was at $\square=0.575 \mathrm{~Hz}$. The values of CWR at $\square=0.525 \mathrm{~Hz}$ are very different between the two curves. For the data with a MWL-CoM distance of around $630 \mathrm{~mm}$, there are two data points at that frequency 


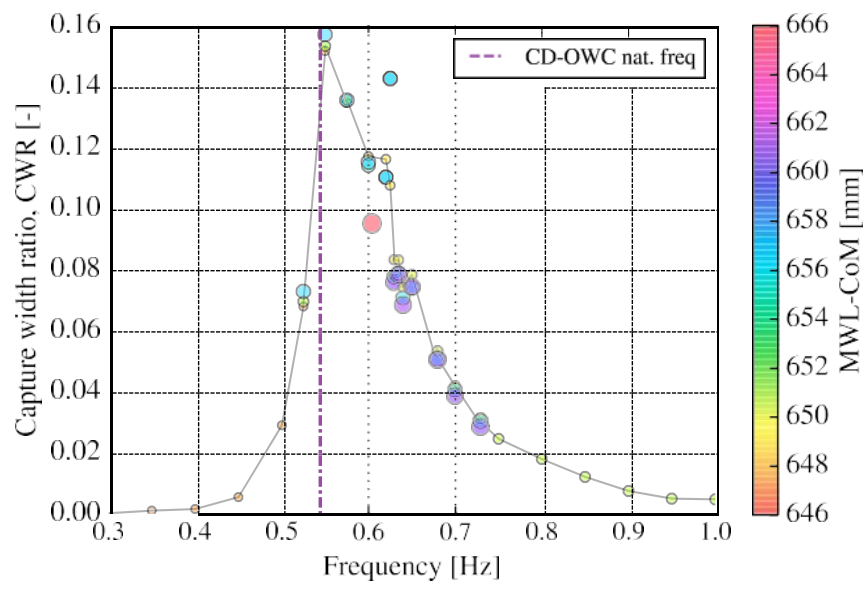

Fig. 14. Capture width ratios for the coaxial-duct OWC for regular waves with $\square=$ $0.10 \mathrm{~m}$ and different frequencies. Series are separated by experimental day with marker colour denoting MWL-CoM distance. The markers' diameter were set proportional to the distance MWL-CoM.

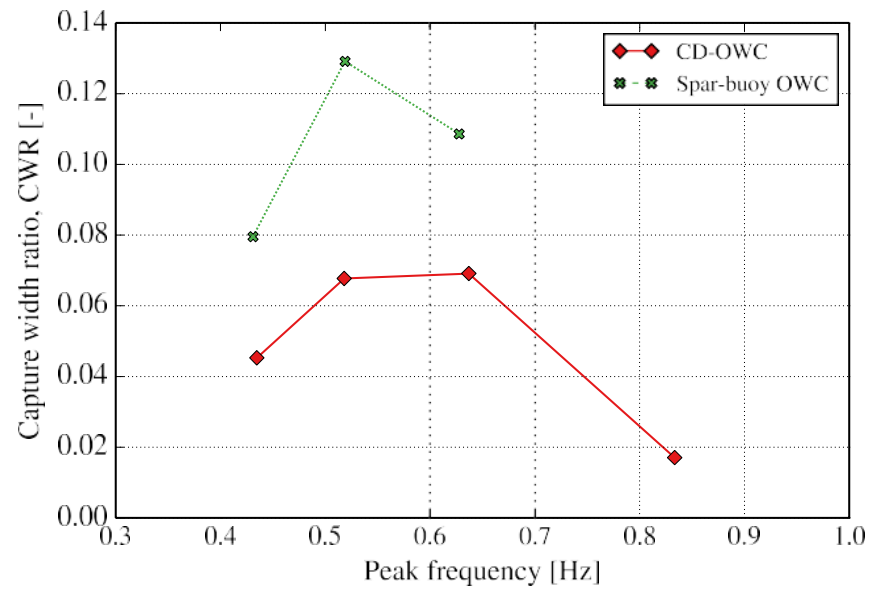

Fig. 15. Capture width ratio for both coaxial-duct and spar-buoy OWCs for PiersonMoskowitz spectra for various peak frequencies and significant wave height, $\square_{\mathrm{s}}=$ $0.056 \mathrm{~m}$.

with the same value, and so it may be assumed that these represent the $C W R$ values. Variations in the CWR peak frequency were expected since the OWC inertia increases with the draught, and therefore the natural frequency decreases.

For the larger regular-wave-height tests ( $\square=0.1 \mathrm{~m}$ ), there was less variation in the MWL-CoM distance, and this resulted in a more consistent CWR curve as shown in Fig. 14. The capture width data was plotted against input frequency with the markers colour-coded based on the MWL-CoM value. The grey curve connects plotted points from the same day and is included to aid interpretation.

As with the smaller wave height, three experiments were conducted for frequencies in the range of $\square=0.525$ and $0.725 \mathrm{~Hz}$. The repeatability of the experiments is good, but exceptions are apparent where there is a difference in the MWL-CoM value, such as between $\square=0.600$ and $0.650 \mathrm{~Hz}$. At $\square=0.600 \mathrm{~Hz}$, the drop in CWR is associated with a larger MWL-CoM value, and this is the result of an experiment run after the first survivability wave test; the increased motion and wave loading may have permitted more water to enter into the device, causing an increase in the MWL-CoM value and a drop in CWR. The latter is important to remark that sometimes the sequence of experiments is important. At $\square$ $=0.625 \mathrm{~Hz}$, the higher marker represents data from two experiments with the same value. Here, a larger MWL-CoM value

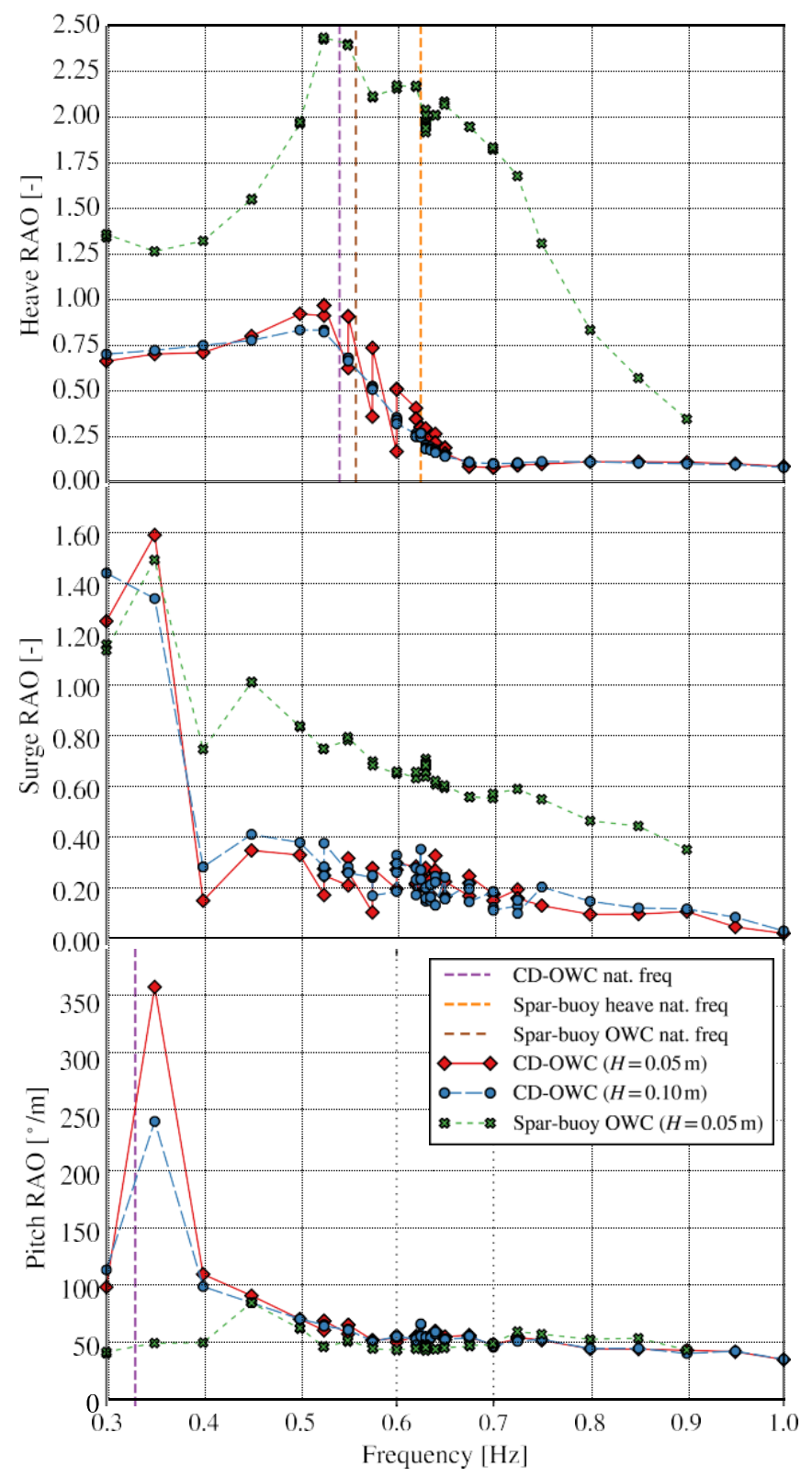

Fig. 16. RAOs for heave, surge and pitch for CD-OWC and spar-buoy OWC under regular waves. The CD-OWC was tested for two wave heights $\square=0.05 \mathrm{~m}$ and $\square=0.10 \mathrm{~m}$, while the spar-buoy OWC was tested only for $\square=0.05 \mathrm{~m}$.

resulted in a larger CWR. Subsequently, for frequencies up to $\square=$ $0.725 \mathrm{~Hz}$, larger MWL-CoM values are associated with lower CWRs.

\subsubsection{Capture width ratio under irregular waves}

Irregular wave tests were performed on both devices for $10 \mathrm{~min}$, which represents approximately one hour at full-scale under operational conditions. Fig. 15 shows results of CWR for irregular waves. Presented values are the average of three tests data. The spar-buoy OWC presents a larger CWR than the CD-OWC, for all peak frequencies. This was already expected from the analysis of the regular-wave CWR values, where the spar-buoy OWC out-performed the CD-OWC for all frequencies (Fig. 12).

In the case of the spar-buoy OWC, the highest CWR value is obtained at a peak frequency of $0.518 \mathrm{~Hz}$, which corresponds to an energy frequency of around $0.610 \mathrm{~Hz}$. This energy frequency is close to the natural frequency in heave of the spar-buoy, and it is within the 


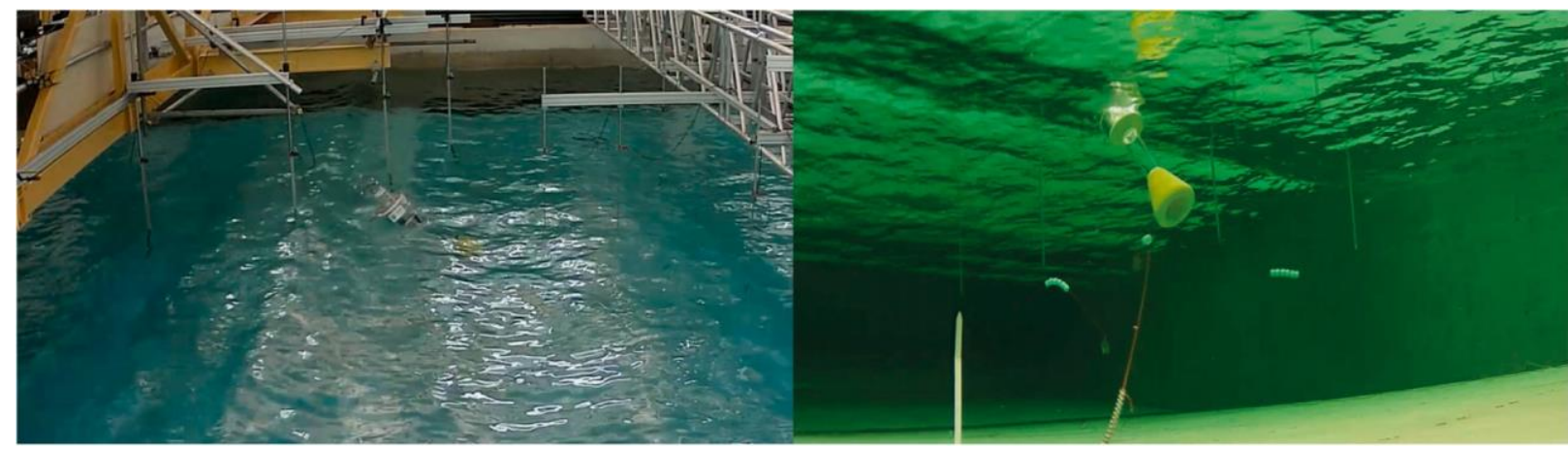

Fig. 17. The spar-buoy model during the survivability test with $\square_{s}=0.325 \mathrm{~m}$ and $\square_{p}=2.91 \mathrm{~s}$.

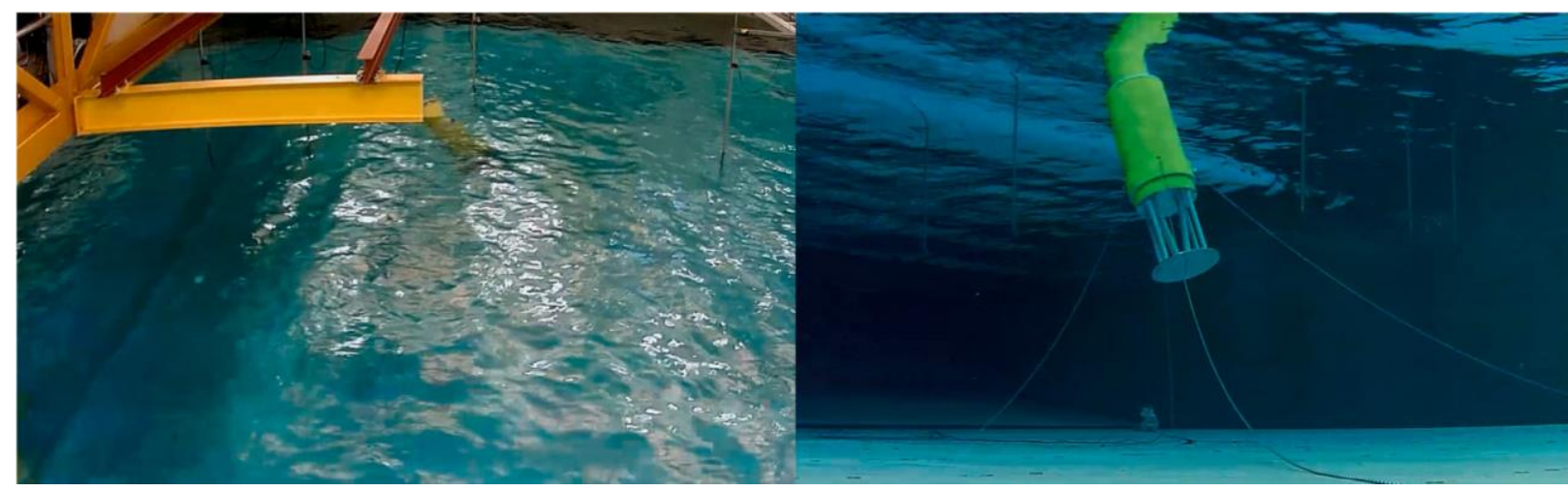

Fig. 18. The CD-OWC model during the survivability test with $\square_{s}=0.325 \mathrm{~m}$ and $\square_{p}=2.91 \mathrm{~s}$.

region of highest CWR under regular waves, as presented in Fig. 12. Therefore, the most relevant frequency components of this spectrum (peak frequency of $0.518 \mathrm{~Hz}$ ) are expected to induce a better irregularwave performance, as seen in Fig. 15. For the CD-OWC, a flatter curve is observed with the highest CWR values at peak frequencies of $0.637 \mathrm{~Hz}$ and $0.518 \mathrm{~Hz}$.

\subsection{Displacements}

The motion of the models in regular waves is commonly characterised through the RAOs. Displacement RAOs are defined as RAO $i=$ $\square_{\square}$, for $\square \in\{1,2,3\}$, or $\mathrm{RAO}_{\square}=\square \Psi_{\square}$, for $\square \in\{4,5,6\}$, where $\square_{i}$ represents the mean amplitude of mode $\square(1=$ surge, $2=$ sway and $3=$ heave), $\mathbb{\square}_{\square}$ represents the mean rotation angle in degrees of mode $\square(4=$ pitch, $5=$ roll and $6=$ yaw $)$, and $\square_{\square}$ the mean amplitude of the waves. The mean displacement amplitudes and rotation angles were obtained from a Fast Fourier Transform.

The test result showed that the CD-OWC has lower displacement amplitudes than the spar-buoy OWC. This may represent an important competitive advantage for applications in sustainable multi-purpose platforms. Fig. 16 presents the RAOs for surge, heave and pitch for the two models tested under regular waves. Results for the RAOs of the CDOWC are presented for two wave heights ( $\square=0.05$ and $0.10 \mathrm{~m}$ ), and only one wave height $(\square=0.05 \mathrm{~m})$ for the spar-buoy. All results are within the limits of repeatability and the limits of the 6-DoF motion tracking system.

It can be observed that the surge RAOs generally increase with the period up to 1.6, as should be expected due to the moorings presence. For the CD-OWC, the heave RAOs slowly increase with the frequency with a peak close to unity at $0.520 \mathrm{~Hz}$, and then decreasing to zero. The spar-buoy has the highest values of RAOs in heave, attaining approximately 2.5 at $0.525 \mathrm{~Hz}$. This is significantly larger compared with the CD-OWC. The pitch RAOs are very similar for both devices. It may be concluded that RAOs have larger amplitudes for the spar-buoy OWC than for the CD-OWC, specially in heave and surge, where CDOWC heave/surge motion seem highly damped, as no clear resonance peak is visible.

\subsection{Survivability in extreme seas}

The survivability experiments subjected the devices to extreme irregular wave conditions by simulating a three-hour full-scale storm. Return periods of 10,50 and 100 years were used to create the waves based on a Pierson-Moskovitz spectrum, defined by peak period $\square_{p}$ and significant wave height $\square_{s}$. Wave overtopping on the devices was expected and frequently occurred during the experiments, so performance data was not calculated. The large motions of the devices, coupled with the overtopping events, meant that the reflective markers on the models associated to the motion acquisition system were not always visible and some motion data had to be interpolated.

The survivability tests performed for the spar-buoy OWC comprised a set of four cases:

$$
\begin{aligned}
& \text { - } \square_{\mathrm{s}}=0.300 \mathrm{~m} \text { and } \square_{\mathrm{p}}=2.72 \mathrm{~s} \\
& \text { - } \square_{\mathrm{s}}=0.325 \mathrm{~m} \text { and } \square_{\mathrm{p}}=2.91 \mathrm{~s} \text {, } \\
& \text { - } \square_{\mathrm{s}}=0.350 \mathrm{~m} \text { and } \square_{\mathrm{p}}=3.06 \mathrm{~s} \text {, } \\
& \text { - } \square_{s}=0.370 \mathrm{~m} \text { and } \square_{p}=3.21 \mathrm{~s}
\end{aligned}
$$

The survivability waves were run for around $30 \mathrm{~min}$ (at model-scale). The maximum tensions in the mooring lines were around $54.8 \mathrm{~N}(3422 \mathrm{kN}$ at full-scale), measured in the lines facing the wave gener- ation system. Fig. 17 shows the spar-buoy OWC under extreme wave tests for $\square_{\mathrm{s}}=$ $0.325 \mathrm{~m}$ and $\square_{\mathrm{p}}=2.91 \mathrm{~s}$.

The survivability tests performed for the CD-OWC comprised a set of only two cases:

- $\square_{s}=0.300 \mathrm{~m}$ and $\square_{p}=2.72 \mathrm{~s}$, 
- $\square_{\mathrm{s}}=0.325 \mathrm{~m}$ and $\square_{\mathrm{p}}=2.91 \mathrm{~s}$.

The survivability tests were abbreviated for this device due to time constraints in the availability of the basin. Tests were run for $30 \mathrm{~min}$ (at model-scale). The maximum tensions were around $13 \mathrm{~N}$ at model- scale ( $812 \mathrm{kN}$ at full-scale), measured in the lines facing the wavemaker for $\square_{\mathrm{s}}$ $=0.325 \mathrm{~m}$ and $\square_{p}=2.91 \mathrm{~s}$. Fig. 18 shows the CD-OWC under extreme waves for the test where the maximum mooring tensions were registered. The results for the mooring line tensions show that the CDOWC has lower peaks in comparison with the spar-buoy OWC, as a consequence of its smaller displacements.

\section{Conclusions}

This paper describes the steps and processes in the physical modelling of wave energy converters in general, with special focus on floating oscillating-water-columns (OWCs). The life cycle of wave energy projects, the model design and the model testing sub-processes were firstly discussed for any wave energy project with a level of detail rarely found in the published literature.

Model design and testing represent perhaps one of the most important stages within the research and development of a wave energy converter. Decision-making needs are always present while testing in a controlled facility/laboratory or offshore. A better knowledge of the processes involved reduces the risk of failures. Experienced gained in the execution of past projects is valuable and may represent the difference between success and failure of an experimental campaign.

There are several critical factors to be considered when planning a test campaign. That includes not only the associated costs, but also the overall strategy, scope of tests, infrastructure selection, measuring instruments and acquisition equipment, plan of resources, risk management, uncertainty analysis, and scheduling. People engaged in the experiments make decisions based on pre-established objectives of the tests. These decisions require specific skills and consciousness of the consequences of decisions before the laboratory or sea tests.

Complementary guidance is obtained through the knowledge of: (i) the processes involved in wave energy projects, focusing on the subprocesses related to physical modelling; ii) the problems that may arise when designing physical models of wave energy converters; iii) the variables involved in the model design process; and (iv) the issues related to the model testing process. This guidance should prevent waste of time and money, and ensure that results are useful for the objectives of internal and/or external stakeholders, such as the scientific community, academia, and investors/entrepreneurs.

The main issues identified in the design and manufacture of the models, as well as in wave tank testing, were illustrated by two sets of tests at 1:40-scale physical models: a spar-buoy OWC and a coaxial-duct (CD) OWC. Results showed that the spar-buoy OWC has larger CWR for a wider range of frequencies under regular and irregular waves in comparison with the CD-OWC. The motion amplitudes of the CD-OWC are smaller than the spar-buoy OWC. This specific characteristic of the CD-OWC may be an advantage for certain offshore applications where large motion amplitudes are undesirable, such as offshore multi-use platforms. Survivability tests were also performed. The higher mooring loads were measured in the spar-buoy OWC model.

Future work should address reductions in uncertainty, duration and costs of model-scale and full-scale testing.

\section{CRediT authorship contribution statement}

J.C.C. Portillo: Conceptualization, Methodology, Software, Formal analysis, Visualization, Writing - original draft. K.M. Collins: Methodology, Software, Data curation, Formal analysis, Visualization, Writing - review \& editing. R.P.F. Gomes: Conceptualization, Methodology, Software, Formal analysis, Visualization, Writing - review \& editing. J.C.C. Henriques: Conceptualization, Software, Visualization, Writing
- review \& editing. L.M.C. Gato: Conceptualization, Supervision, Writing - review \& editing, Validation, Funding acquisition. B.D. Howey: Methodology, Formal analysis, Software, Data curation, Validation.

M.R. Hann: Methodology, Data curation, Validation. D.M. Greaves: Conceptualization, Supervision, Writing - review \& editing, Validation, Funding acquisition. A.F.O. Falcão: Supervision, Writing - review \& editing.

\section{Declaration of competing interest}

The authors declare that they have no known competing finan- cial interests or personal relationships that could have appeared to influence the work reported in this paper.

\section{Acknowledgements}

This work was supported by the European Union's Horizon 2020 programme, under the Wave Energy Transition to Future by Evolution of Engineering and Technology project (WETFEET) with grant agreement No 641334. It was also funded by the Portuguese Foundation for Science and Technology (FCT) through IDMEC, under LAETA, project UIDB/50022/2020.

\section{References}

[1] Pecher A, Costello R. Techno-economic development of WECs. Cham: Springer International Publishing; 2017, p. 221-60. http://dx.doi.org/10.1007/978-3- 31939889-1 9.

[2] HMRC. Ocean energy: Development and evaluation protocol. Part 1: Wave power. Cork, Ireland: Hydraulics and Maritime Research Centre (HMRC); 2003, Retrieved on 01/06/2020. URL https://www.seai.ie/publications/HMRCProtocall.pdf.

[3] Falcão AFO, Henriques JCC. Model-prototype similarity of oscillating-watercolumn wave energy converters. Int J Marine Energy 2014;6:18-34. http://dx. doi.org/10.1016/j.ijome.2014.05.002.

[4] Makins JC. Technology readiness levels, A white paper, 22 December, 2004. 1995, p. $1-5$.

[5] Nielsen K. Annex II Report 2003: Development of recommended practices for testing and evaluating ocean energy systems. Denmark: Ramboll; 2003.

[6] Holmes B. Tank testing of wave energy conversion systems. Marine renewable energy guides. Orkney, Scotland: EMEC; 2009

[7] IEE. State of the art analysis. A cautiously optimistic review of the technical status of wave energy technology. Report of Waveplam. Brussels, Belgium: Intelligent Energy Europe;2009.

[8] Weber J. WEC technology readiness and performance matrix - finding the best research technology development trajectory. In: Proc. of the 4th International Conference on Ocean Energy, ICOE'12, Dublin. Dublin, Ireland; 2012.

[9] Weber J. Optimisation of the hydrodynamic-aerodynamic coupling of an Oscillat-ing Water Column wave energy device [Ph.D. thesis], Ireland: University College Cork; 2006.

[10] Heller V. 8.04 - development of wave devices from initial conception to commercial demonstration. In: Sayigh A, editor. Comprehensive renewable energy. Oxford: Elsevier; 2012, p. 79-110. http://dx.doi.org/10.1016/B978-0- 08087872-0.00804-0.

[11] Pecher A. Experimental testing and evaluation of WECs. In: Handbook of ocean wave energy. Cham: Springer International Publishing; 2017, p. 221-60. http: //dx.doi.org/10.1007/978-3-319-39889-1 9.

[12] Hann M, Perez-Collazo C. 7. Physical modelling. In: Greaves D, Iglesias G, editors. Wave and tidal energy. Hoboken, NJ: Wiley; 2018, p. 233-88.

[13] Roberts JD, Bull DL, Malins RJ, Costello RP, Babarit A, Nielsen K, et al. Technology performance level assessment methodology. Technical report SAND2017-4471 652836, United States: Sandia National Lab.; 2017, http://dx. doi.org/10.2172/1365530.

[14] IEC. Marine energy - Wave, tidal and other water current converters - Part 103: Guidelines for the early stage development of wave energy converters - Best practices and recommended procedures for the testing of pre-prototype devices. Technical report IEC TS 62600-103:2018, Geneva, $\mathrm{CH}$ : International Electrotechnical Commission; 2018.

[15] Day S, Penesis I, Babarit A, Fontaine A, He Y, Kraskowski M, et al. Wave energy converter model test experiments. In: Proceedings of the 27th international towing tank conference (recommended procedures and guidelines register), 31 August - 5 September, Copenhagen, Denmark; 2014. p. 1-13.

[16] EquiMar. Equitable testing and evaluation of marine energy extraction devices in terms of performance, cost and environmental impact. Brussels, Belgium: European Commission; 2011 
[17] European Commission. Horizon 2020: WORK PROGRAMME 2016-2017 General Annexes. 2016, URL https://ec.europa.eu/research/participants/data/ ref/h2020/other/wp/2016-2017/annexes/h2020-wp1617-annex-ga_en.pdf. Retrieved on 01/06/2020.

[18] Falcão AFO, Sarmento AJNA, Gato LMC, Brito-Melo A. The Pico OWC wave power plant: Its lifetime from conception to closure 1986-2018. Appl Ocean Res 2020;98:102104. http://dx.doi.org/10.1016/j.apor.2020.102104.

[19] Carrelhas AAD, Gato LMC, Henriques JCC, Falcão AFO, Varandas J. Test results of a $30 \mathrm{~kW}$ self-rectifying biradial air turbine-generator prototype. Renew Sustain Energy Rev 2019;109:187-98. http://dx.doi.org/10.1016/j.rser.2019.04.008.

[20] Masuda Y, Yamazaki T, Outa Y, McCormick ME. Study of backward bent duct buoy, OCEANS'87, NS, Canada. 1987, p. 384-9. http://dx.doi.org/10.1109/ OCEANS.1987.1160750

[21] Falcão AFO, Henriques JCC. Oscillating-water-column wave energy converters and air turbines: A review. Renew Energy 2016;85:1391-424. http://dx.doi.org/ 10.1016/j.renene.2015.07.086.

[22] Gomes RPF, Henriques JCC, Gato LMC, Falcão AFO. Time-domain simulation of a slack-moored floating oscillating water column and validation with phys- ical model tests. Renew Energy 2020;149:165-80. http://dx.doi.org/10.1016/j. renene.2019.11.159.

[23] Gomes RPF, Henriques JCC, Gato LMC, Falcão AFO. Wave power extraction of a heaving floating oscillating water column in a wave channel. Renew Energy 2016;99:1262-75. http://dx.doi.org/10.1016/j.renene.2016.08.012.

[24] Benreguig P, Pakrashi V, Murphy J. Assessment of primary energy conversion of a closed-circuit OWC wave energy converter. Energies 2019;12(10):1962. http://dx.doi.org/10.3390/en12101962.

[25] Sarmiento J, Iturrioz A, Ayllón V, Guanche R, Losada IJ. Experimental modelling of a multi-use floating platform for wave and wind energy harvesting. Ocean Eng 2019;173:761-73. http://dx.doi.org/10.1016/j.oceaneng.2018.12.046.

[26] Singh U, Abdussamie N, Hore J. Hydrodynamic performance of a floating offshore OWC wave energy converter: An experimental study. Renew Sustain Energy Rev 2020;117:1-18. http://dx.doi.org/10.1016/j.rser.2019.109501.

[27] Mazarakos T, Konispoliatis D, Katsaounis G, Polyzos S, Manolas D, Voutsinas S, et al. Numerical and experimental studies of a multi-purpose floating TLP structure for combined wind and wave energy exploitation. Mediterr Mar Sci 2019;20(4):74563. http://dx.doi.org/10.12681/mms.19366.

[28] Moretti G, Santos Herran M, Forehand D, Alves M, Jeffrey H, Vertechy R, et al. Advances in the development of dielectric elastomer generators for wave energy conversion. Renew Sustain Energy Rev 2020;117. http://dx.doi.org/10.1016/j. rser.2019.109430.

[29] Wu M, Stratigaki V, Troch $\mathrm{P}$, Altomare $\mathrm{C}$, Verbrugghe $\mathrm{T}$, Crespo A, et al. Experimental study of a moored floating oscillating water column wave-energy converter and of a moored cubic box. Energies 2019;12(10):18-34. http://dx. doi.org/10.3390/en12101834.

[30] Howe D, Nader J-R, Macfarlane G. Experimental investigation of multiple oscillating water column wave energy converters integrated in a floating breakwater: Energy extraction performance. Appl Ocean Res 2020;97:1-18. http://dx.doi.org/ 10.1016/j.apor.2020.102086.

[31] Correia da Fonseca FX, Gomes RPF, Henriques JCC, Gato LMC, Falcão AFO. Model testing of an oscillating water column spar-buoy wave energy converter isolated and in array: Motions and mooring forces. Energy 2016;112:1207-18. http://dx.doi.org/10.1016/j.energy.2016.07.007.

[32] Gao Z, Moan T, Wan L, Michailides C. Comparative numerical and experimental study of two combined wind and wave energy concepts. J Ocean Eng Sci 2016;1(1):36-51. http://dx.doi.org/10.1016/j.joes.2015.12.006.

[33] Zhang H, Zhou B, Vogel C, Willden R, Zang J, Zhang L. Hydrodynamic performance of a floating breakwater as an oscillating-buoy type wave energy converter. Appl Energy 2020;257:1-19. http://dx.doi.org/10.1016/j.apenergy. 2019.113996.
[34] Kamarlouei M, Gaspar JF, Calvario M, Hallak TS, Mendes MJGC, Thiebaut F, et al. Experimental analysis of wave energy converters concentrically attached on a floating offshore platform. Renew Energy 2020;152:1171-85. http://dx.doi.org/ 10.1016/j.renene.2020.01.078

[35] Zhao X, Ning D. Experimental investigation of breakwater-type WEC composed of both stationary and floating pontoons. Energy 2018;155:226-33. http://dx. doi.org/10.1016/j.energy.2018.04.189.

[36] Henriques JCC, Gato LMC, Falcão AFO, Robles E, Faÿ F-X. Latching control of a floating oscillating-water-column wave energy converter. Renew Energy 2016;90:229-41. http://dx.doi.org/10.1016/j.renene.2015.12.065.

[37] Elhanafi A, Macfarlane G, Fleming A, Leong Z. Experimental and numerical investigations on the hydrodynamic performance of a floating-moored oscillating water column wave energy converter. Appl Energy 2017;205:369-90. http://dx. doi.org/10.1016/j.apenergy.2017.07.138.

[38] Falcão AFO, Henriques JCC. The spring-like air compressibility effect in oscillating water-column wave energy converters: Review and analyses. Renew Sustain Energy Rev 2019;112:483-98. http://dx.doi.org/10.1016/j.rser.2019.04. 040.

[39] Elhanafi A, Macfarlane G, Fleming A, Leong Z. Scaling and air compressibility effects on a three-dimensional offshore stationary OWC wave energy converter. Appl Energy 2017;189:1-20. http://dx.doi.org/10.1016/j.apenergy.2016.11.095.

[40] Henriques JCC, Portillo JCC, Gato LMC, Gomes RPF, Ferreira DN, Falcão AFO Design of oscillating-water-column wave energy converters with an application to self-powered sensor buoys. Energy 2016;112:852-67. http://dx.doi.org/10.1016/ j.energy.2016.06.054.

[41] Hughes SA. Physical models and laboratory techniques in coastal engineering World Scientific Publishing; 1993

[42] Chakrabarti SK. Handbook of offshore engineering. Elsevier; 2005.

[43] Henriques JCC, Gomes RPF, Gato LMC, Falcão AFO, Robles E, Ceballos S. Testing and control of a power take-off system for an oscillating-water-column wave energy converter. Renew Energy 2016;85:714-24. http://dx.doi.org/10.1016/j. renene.2015.07.015.

[44] Zabala I, Henriques JCC, Blanco JM, Gomez A, Gato LMC, Bidaguren I, et al. Wave-induced real-fluid effects in marine energy converters: Review and application to OWC devices. Renew Sustain Energy Rev 2019;111:535-49. http //dx.doi.org/10.1016/j.rser.2019.05.025.

[45] Portillo JCC, Falcão AFO, Henriques JCC, Gato LMC. Experimental compress- ibility study on a Coaxial-Duct OWC. In: 13th European wave and tidal energy conference, 1-6 of September 2019, Naples, Italy.

[46] Collins K, Howey B, Greaves D, Hann M, Iglesias G, Gomes RPF, et al. D6.5- Design guidance on the use of shared moorings in compact arrays. WETFEET EU Funded Project: 2018.

[47] Harnois V, Collins K, Greaves D, Howey B, Gomes RPF, Portillo JCC, et al. D6.4 Validated numerical simulation of hydrodynamic interaction between devices for different compact array layouts. WETFEET EU Funded Project; 2018.

[48] Gomes RPF, Henriques JCC, Gato LMC, Falcão AFO. Hydrodynamic optimization of an axisymmetric floating oscillating water column for wave energy conver sion. Renew Energy 2012;44:328-39. http://dx.doi.org/10.1016/j.renene.2012. 01.105.

[49] Portillo JCC, Henriques JCC, Gato LMC, Gomes RPF, Falcão AFO. Perfor mance assessment of a floating coaxial-ducted OWC wave energy converter fo oceanographic purposes. In: Proceedings of the ASME 2015 34th interna- tiona conference on ocean, offshore and arctic engineering. Volume 9: Ocean renewable energy, St. John's, Newfoundland, Canada. May 31-June 5. 2015, http://dx.doi.org/10.1115/OMAE2015-41975.

[50] Chakrabarti SK. Offshore structure modeling. World Scientific Publishing Co 1994, http://dx.doi.org/10.1142/2127.

[51] Greaves D. 3. Wave energy technology. In: Greaves D, Iglesias G, editors. Wave and tidal energy. Hoboken, NJ: Wiley; 2018, p. 52-104.

[52] Collins KM, Stripling S, Simmonds DJ, Greaves DM. Quantitative metrics for evaluation of wave fields in basins. Ocean Eng 2018;169:300-14. http://dx.doi. org/10.1016/j.oceaneng.2018.09.010. 